\title{
Actual Extreme Pressure Distributions and LRC Formula
}

\author{
Yukio Tamura ${ }^{\text {1), }}$, Hirotoshi Kikuchi ${ }^{2)}$ and Kazuki Hibi ${ }^{2)}$ \\ 1) Department of Architectural Engineering, Tokyo Institute of Polytechnics, Kanagawa 243-0297, Japan \\ 2) Research Institute of Technology, Shimizu Corporation, Kohtohku, Tokyo 135-8530, Japan
}

\section{INTRODUCTION}

Holmes $^{1)}$ studied the actual distributions of instantaneous wind pressures along a gabled roof frame producing peak loads and load effects on the frame of a low-rise building model. The load-response-correlation (LRC) formula was proposed by Kasperski ${ }^{2}$ to realistically model the spatial distribution of wind loads that produce accurate peak structural responses. Holmes ${ }^{3)}$ extended the LRC approach to incorporate proper orthogonal decomposition (POD).

Tamura et al. ${ }^{4)}$ discussed the actual extreme wind load distributions $\hat{C}_{p}$ causing the maximum and minimum stresses in members of the structural frames on the basis of 154 samples of 10-min length in full-scale conversion, and compared the results with those $\left(C_{L R C}\right)$ computed from Kasperski's LRC formula. Although the LRC formula seemed to be valid for general cases, the results suggested that the validity depended on the frame location.

The LRC pressure $p(j)_{Y}$ at a point $j$ causing the peak value of a load effect $Y$ is based on the covariance $\overline{p_{i} p_{j}}$ of wind pressures as follows

$p(j)_{Y}=\bar{p}(j)+g_{Y} \sigma_{p j} \sum_{i=1}^{n}\left(\overline{p_{i} p_{j}} a_{Y i}\right) / \sigma_{Y}$

Here, $\sigma_{p j}$ and $\sigma_{Y}$ are the standard deviations of the pressure at $j$ and the load effect $Y . g_{Y}$ is the peak factor of the load effect $Y$, and $a_{Y_{i}}$ is the influence coefficient. Thus, the temporal average characteristics of the wind pressures are reflected in the LRC pressure distribution $C_{L R C}$. Therefore, if the maximum load effects are generated by some extreme conditions that differ from the temporal average characteristics of the pressure field, the LRC pressure distribution can differ from the actual extreme pressure distribution.

This paper compares the three wind load distributions, $\hat{C}_{p}, C_{L R C}$ and $G C_{p}$, for frames set at different locations in the low-rise building models.
The wind pressure data are the same as those used in Tamura et al. ${ }^{4}$. 154 samples of 10-min length were analyzed for the urban flow with a power-law index $\alpha$ $=1 / 4$. Each sample is a data-set of fluctuating wind pressures at 512 points uniformly distributed on the surface of the low-rise building model with a square plan.

\section{FRAME LOCATIONS AND MEAN PRESSURE DISTRIBUTIONS}

The frame locations are indicated in Fig.1. Frames$\mathrm{La}, \mathrm{Lb}$ and $\mathrm{Lc}$ are set in the along-wind direction, and Frames- $\mathrm{Ca}, \mathrm{Cb}, \mathrm{Cc}$ and $\mathrm{Cd}$ are set in the across-wind direction. The mean pressure coefficients on each frame are shown in Fig.2. The mean pressure for the along-wind frames has the maximum suction at the windward end, showing a slightly different pattern for Frame-La located at the periphery of the roof. The mean pressure patterns for across-wind Frames-Cc and $\mathrm{Cd}$ are uniform and almost the same, showing that they are located in the reattached region.

The peak factors of the pressures were larger for the negative side except for the windward wall. The
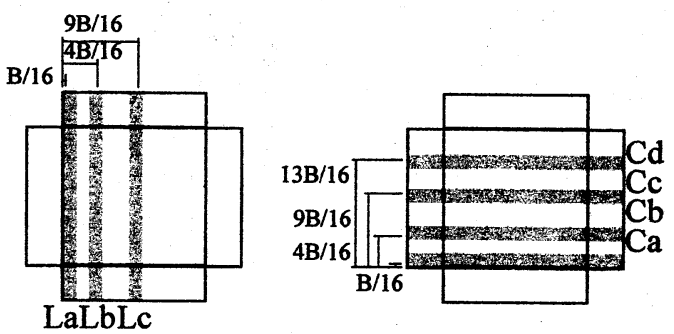

(a) Along- ld Frames (b) Across-wir rames

Fig.1 Frame locations 


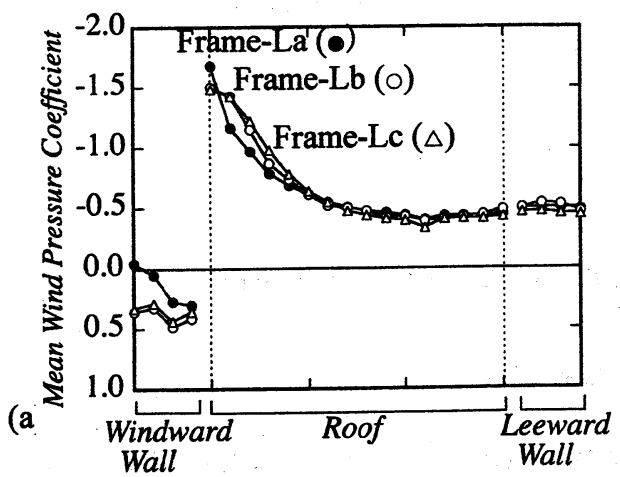

(b)

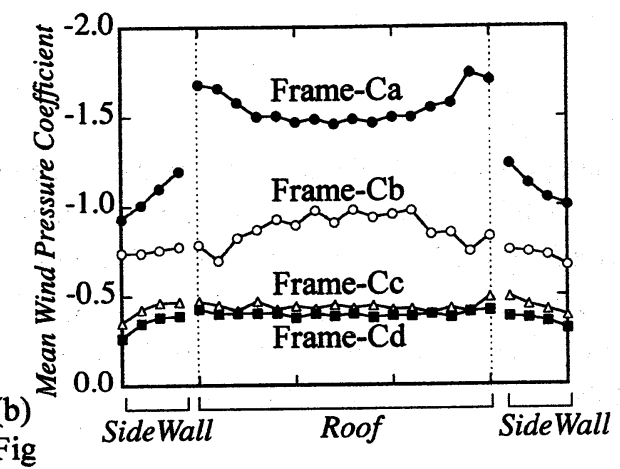

negative side peak factors of the roof pressures on the periphery frames, i.e. Frame-La and Frame-Ca, are almost constant over the span, showing a large value of more than (-)6.

\section{PEAK FACTORS OF INTERNAL FORCES}

The LRC formula requires the peak factor $g_{Y}$ of the load effects, and Kasperski ${ }^{2)}$ tentatively adopted 3.5. In this study, the peak factor for each load effect could be obtained in the process of calculating the maximum load effects. Here, considering the load combinations with dead load or snow load, the internal forces due to the positive side and negative side roof pressure fluctuations were calculated and the results are indicated by $Q^{+}, M^{+}, Q^{-}$and $M^{-}$, where the sign means positive or negative side load effect.

Ensemble averaged peak factors of the internal forces for 154 samples are shown in Table 1. The sign of each internal force is indicated by + and - attached to the peak factor. For the negative side load effects $Q^{-}$and $M^{-}$, the peak factor changes in the range 4.2 5.4, while much smaller peak factors in the range 1.9 3.9 are obtained for the positive side load effects $Q^{+}$ and $\mathrm{M}^{+}$. The peak factors were less affected by the flow and column base conditions.
Table 1 Peak factors of internal forces in frames (pin-roller base condition)

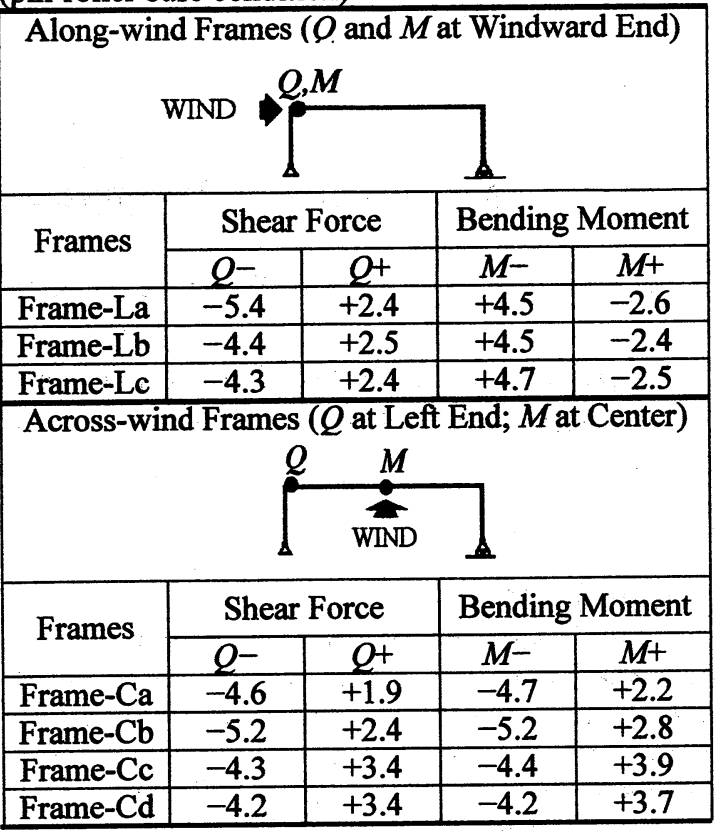

\section{EXTREME PRESSURE DISTRIBUTIONS}

The instantaneous pressure distributions causing the maximum quasi-static internal forces, i.e. shear force $Q$ and bending moment $M$ in the end and the center of the beam, were extracted from each 10-min sample in full-scale conversion. Then, the ensemble averaged instantaneous pressure distribution over 154 samples was defined as "actual extreme wind load $\hat{C}_{p}$ " causing the maximum load effect.

The extreme wind pressure distribution due to Kasperski's LRC formula, which is defined as "LRC extreme wind load $C_{L R C}$ ", was also calculated from Eq.(1) using the peak factor obtained in the previous section for each load effect.The "quasi-steady wind load $G C_{p}$ ", which is the product of the mean pressure distributions $C_{p}$ and the ensemble averaged gust effect factor for each load effect $G\left(=M_{\max } / M_{\text {mean }}\right.$ or $Q_{\max } /$ $Q_{\text {mean }}$ ), was also evaluated. The gust effect factors of load effects were in the range of 2.4 - 3.1 and much less than the square of the gust factor of the approaching flow $G_{V}{ }^{2}=4.3$.

The above three extreme wind loads for estimating maximum load effect are compared in Figs. 3 and 4 for the along-wind frames (Frames-La, Lb and $\mathrm{Lc}$ ) and across-wind frames (Frames-Ca, $\mathrm{Cb}$ and $\mathrm{Cc}$ ), respectively. As expected from Fig.2(b), the result for 
$-(-) \cdots \cdot \cdot(+):$ Actual $\hat{C}_{p} \quad \bullet(-) \Delta(+):$ LRC $C_{L R C}$
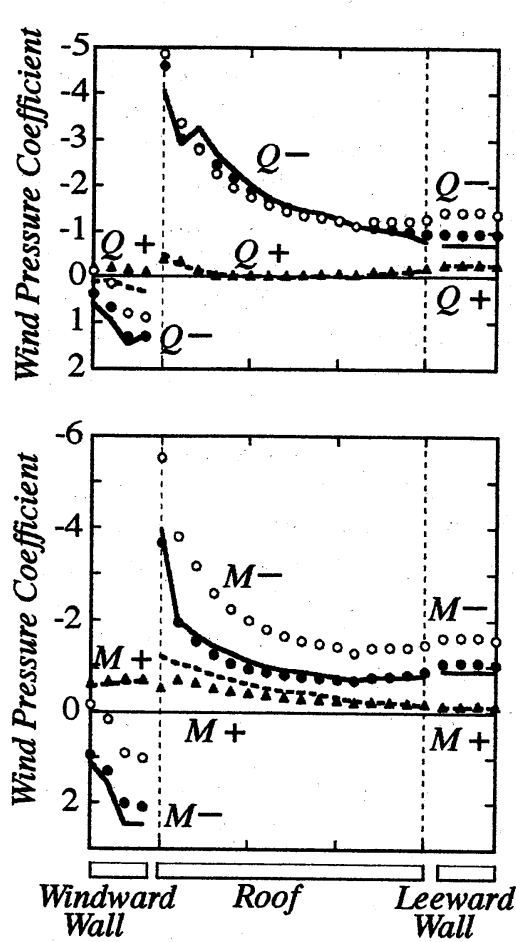

(a) Frame-La

Fig.3 Extreme wind loads (Along-wind frames, $Q$ and $M$ at windward end) $\bigcirc$ : Quasi-steady $G C_{p}$
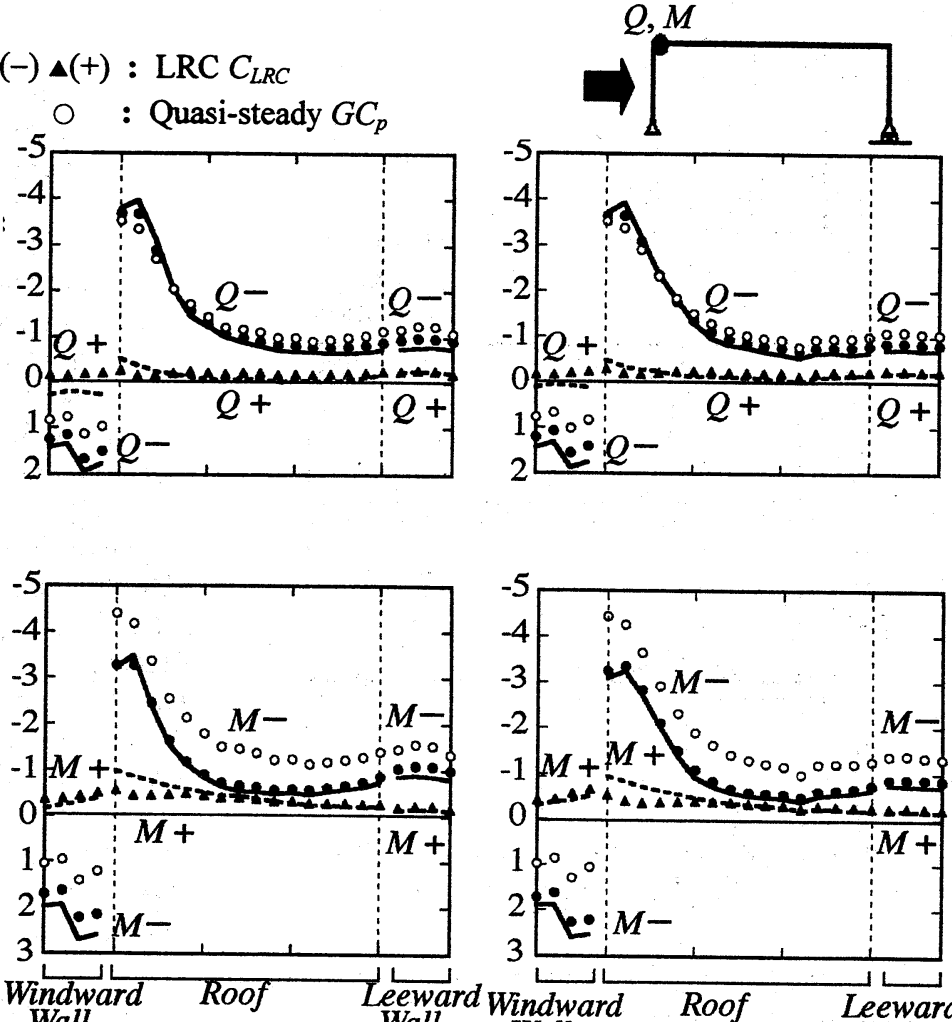

Wall

(b) Frame-Lb

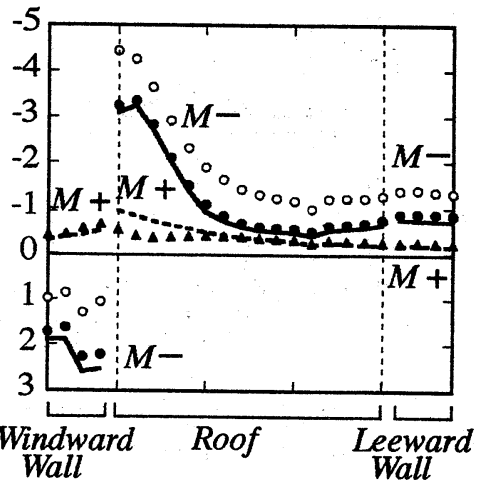

(c) Frame-Lc
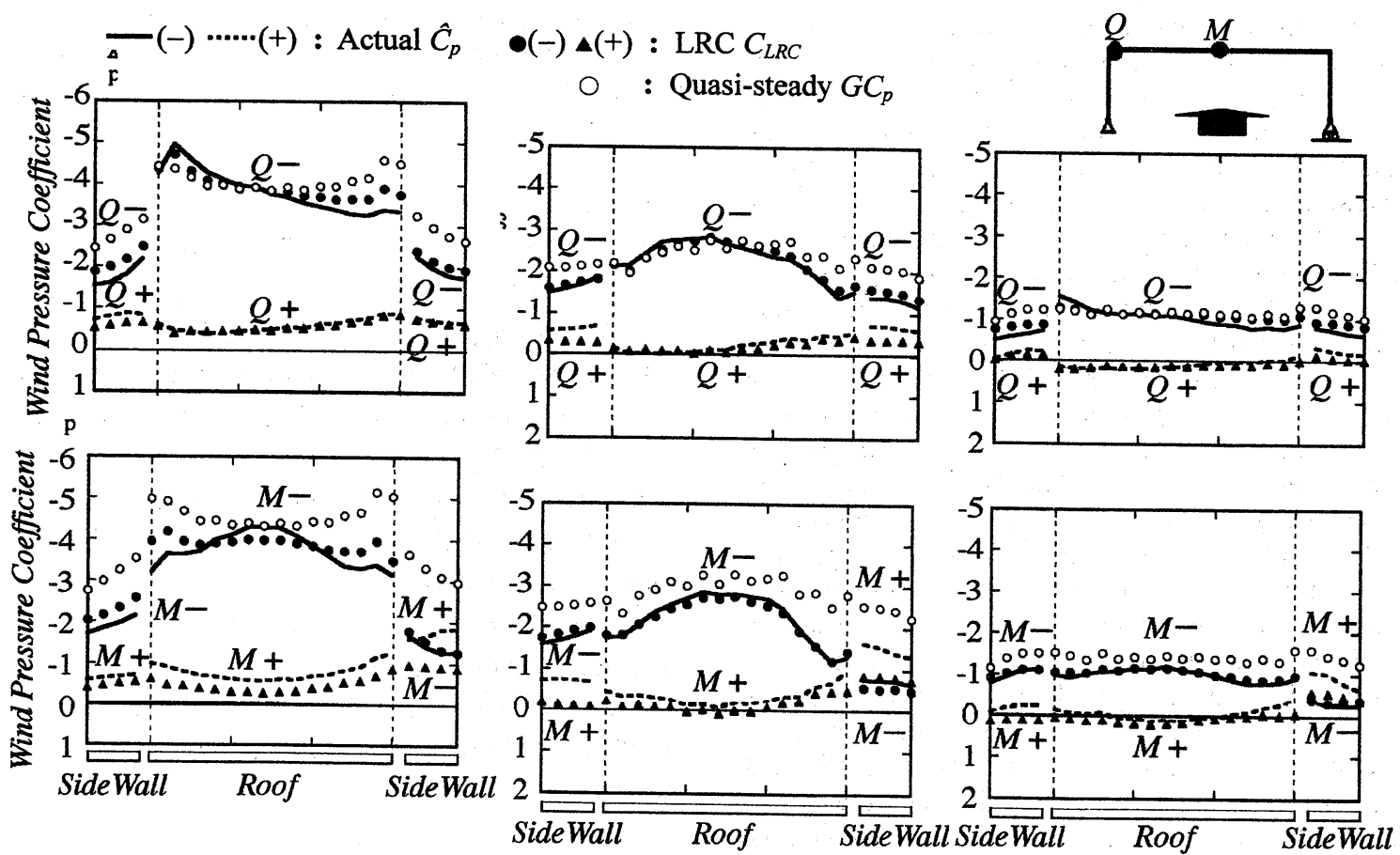

(a) Frame-Ca

(b) Frame- $\mathrm{Cb}$

(c) Frame-Cc

Fig.4 Extreme wind loads (Across-wind frames, $Q$ at left end, $M$ at center) 

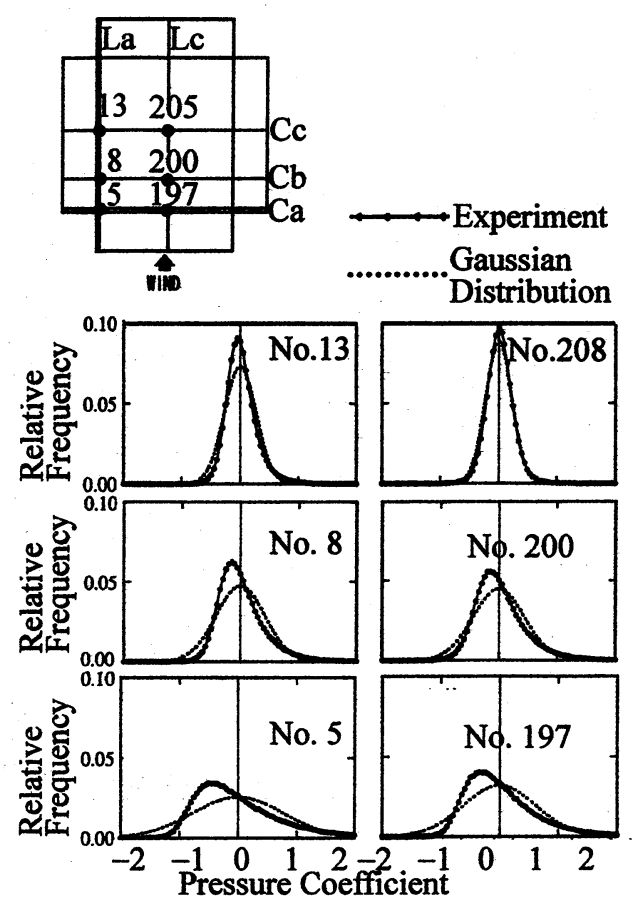

Fig.5 Frequency distributions of fluctuating pressures at several points

Frame-Cd was almost the same as that for Frame-Cc.

As is clearly seen in Fig.3 for the windward end bending moment $M$ and shear force $Q$ of along-wind frames, the LRC wind load $C_{L R C}(\bullet)$ agrees well with the actual $\hat{C}_{p}$ (solid lines), especially for the negative side roof pressure, as Holmes ${ }^{3)}$ reported for a fixed base frame model. For shear force $Q^{-}$, the quasi-steady $G C_{p}(0)$ on the roof is similar to the actual $\hat{C}_{p}$ and LRC $C_{L R C}$, although $C_{L R C}$ is always closer to the actual $\hat{C}_{p}$. However, the quasi-steady $G C_{p}$ differs from the actual wind load $\hat{C}_{p}$ for bending moment $M^{-}$. The ratio of the suction near the leading edge to that in the reattached region is approximately 6 for the actual $\hat{C}_{p}$, while it is 3 for the quasi-steady $G C_{p}$. For this pin-roller frame, the negative quasi-steady $G C_{p}$ on the roof and leeward wall is much larger than the actual $\hat{C}_{p}$, although the quasi-steady $G C_{p}$ on the windward wall is almost half of the actual $\hat{C}_{p}$. For the positive side pressure distribution for $\mathrm{M}^{+}$, the LRC wind load ( $\Delta$ ) becomes smaller than the actual $\hat{C}_{p}$ (broken lines) near the leading edge of the roof. These tendencies are commonly observed regardless of the frame location.

As seen in Fig.4 for the across-wind frames, the actual extreme pressure $\hat{C}_{p}$ varies significantly with the frame location. For the left end shear force $Q^{-}$, the actual $\hat{C}_{p}$ tends to cluster to the left side, and the LRC $\mathrm{C}_{L R C}$ follows this tendency. However, the quasi-steady $G C_{p}$ is symmetric and different from the actual $\hat{C}_{p}$.
For Frame-Ca, located very close to the leading edge, even the LRC $C_{L R C}$ does not agree with the actual $\hat{C}_{p}$. The discrepancy becomes more significant for the beam center bending moment $M^{-}$. As seen in Fig.4(a) for Frame- $\mathrm{Ca}$, the actual $\hat{C}_{p}$ has a gentle peak near the center of the roof, while the quasi-steady $G C_{p}$ has peaks at both ends of the roof. The quasi-steady $G C_{p}$ is much larger than the actual $\hat{C}_{p}$ except at the roof center, and the LRC $C_{L R C}$ has a similar pattern to the quasi-steady $G C_{p}$. For both Frame-Cb in the separation bubble region and Frame-Cc in the reattached region, $L R C C_{L R C}$ agree very well with the actual $\hat{C}_{p}$.

One of the reasons for the discrepancy between the LRC $C_{L R C}$ and the actual $\hat{C}_{p}$ may be attributed to the following. Fig. 5 shows examples of the relative frequency distributions of the fluctuating pressures. The distributions of No.5 and No.197 significantly skew from the Gaussian distribution indicated by dotted line in the figures. The entire span of Frame-Ca is immersed in the non-Gaussian and unsteady pressure field. The extreme conditions causing the maximum load effects can differ from the temporal average characteristics assumed in the LRC formula.

\section{CONCLUDING REMARKS}

The validity of Kasperski's LRC formula was proved to estimate the actual extreme wind load for the general location of the frame including the separation bubble region. The only exception was where the frame was immersed in the vicinity of the leading edge, where the non-Gaussian characteristics are predominant and unsteady pressure fluctuations are observed.

\section{Reference}

1) Holmes, J.D., Distribution of peak wind loads on a low-rise building, Journal of Wind Engineering and Industrial Aerodynamics, 29, 59-67, 1988.

2) Kasperski, M., Extreme wind load distributions for linear and nonlinear design", Engineering Structures, 14(1), 27- 34, 1992.

3) Holmes, J.D., Optimised peak load distributions, Journal of Wind Engineering and Industrial Aerodynamics, 41-44, 267-276, 1992.

4) Tamura, Y., H. Kikuchi and K. Hibi, Extreme wind pressure distributions on low-rise building models, Abstract Volume, Fourth International Colloquium on Bluff Body Aerodynamics and Applications, Ruhr University, Bochum, Germany

Keywords : quasi-steady, quasi-static, LRC, extreme pressure distribution, load effect, internal force 


\title{
A Knowledge-Based Expert System for Wind Resistant Design of Reinforced Concrete Chimneys
}

\author{
Jenmu Wang, Horng-Shen Wen and Chii-Ming Cheng \\ Department of Civil Engineering, Tamkang University, Tamsui, Taipei Hsien, Taiwan
}

\section{INTRODUCTION}

Wind effects on tall structures are important issues. Especially, chimneys are a kind of static determined structure. A local structural failure can lead to the total lost of the whole structure. Hence, sensibly analyzing the wind load condition in order to design economic and safe chimneys is the main motivation of our research. The design codes and regulations for wind resistant design are usually complex and prone to misinterpretations. Besides, a high-quality design is not only based on strict structural theory but also accompanied with accumulated design experience. So the goal of the research is to develop a knowledge-based expert system, which incorporates theory of wind engineering, code of structural design and experience-based knowledge of design engineers, for the design of circular cylinder structures subjected to wind loads.

Current design specifications are based on empirical formulas and equivalent static load distributions resulting from simplified dynamic analyses. This approach cannot fully reflect the random characteristics of wind loads. A focus of the research is to develop a design system that takes the aerodynamic damping and aeroelastic lock-in phenomena between a structure and oncoming flow into consideration. In the aspect of structural design, this system refers to the most common standards-standard practice for the design and construction of cast-in-place reinforced concrete chimneys ACI 307-98.

Kappa-PC, an expert system building tool developed by Intellicorp, was used to implement the system. Based on the character of the knowledge to be represented, rule-based reasoning and object-oriented programming were used accordingly to code the system. In addition, the system integrates numerical and structural analysis programs together with a friendly user interface to perform wind load analysis and chimney design. Lastly, documented cases from literature were used to test the accuracy of the system.

\section{BACKGROUND}

Expert system is the most notable application of AI (Artificial Intelligence) ${ }^{1)}$. It is a computer program intended to solve a professional problem and based on the heuristic knowledge of domain experts. The domain knowledge is formalized with declarative symbols and processed using logic reasoning.

Knowledge-based expert system is a better name for today's sophisticated intelligence systems, which integrate the surface and deep knowledge of application domains to resolve problems. Usually a mixture of information technologies has to be utilized to integrate different application software and deliver expert systems as embedded systems.

Although expert systems have been applied to many fields for many years, internal applications usually do not expose to the public. Still successful cases have been reported from time to time. In the field of civil engineering, a survey of various expert system applications can be found in literature ${ }^{2,3,4)}$. As for the application of expert system in wind engineering, only few studies have been reported ${ }^{5}$.

\section{SYSTEM DESIGN PROCEDURE}

When a structure with circular cross section subjects to wind loads, the application point of the resultant wind force is at the mass center. Since the axial symmetric geometry, the center of rigidity coincides with the mass center. There is no torsional effect. Therefore, only 


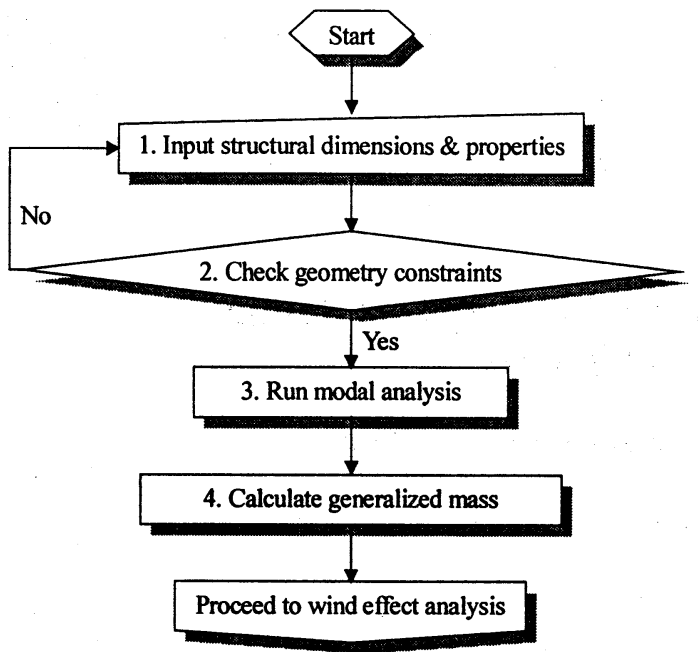

Fig. 1. Structural Analysis Procedure

along-wind and across-wind loading need to be considered in the design of circular cylinder structures. Analytical model, such as gust factor approach, can be used to predict along-wind response with reasonable accuracy. Consequently, we can use structural dynamics and random vibration theories to make a reasonable analysis. As for across-wind response, we adopt the aerodynamic damping analysis model brought out by Vickery and Basu in $1983^{6,7)}$. The preliminary designs of chimneys suggested by the system are based on ACI 307-98 and ACI 307R-98.

The structural analysis and design process of the system consists of four stages:

- Structural Analysis-The first stage is shown

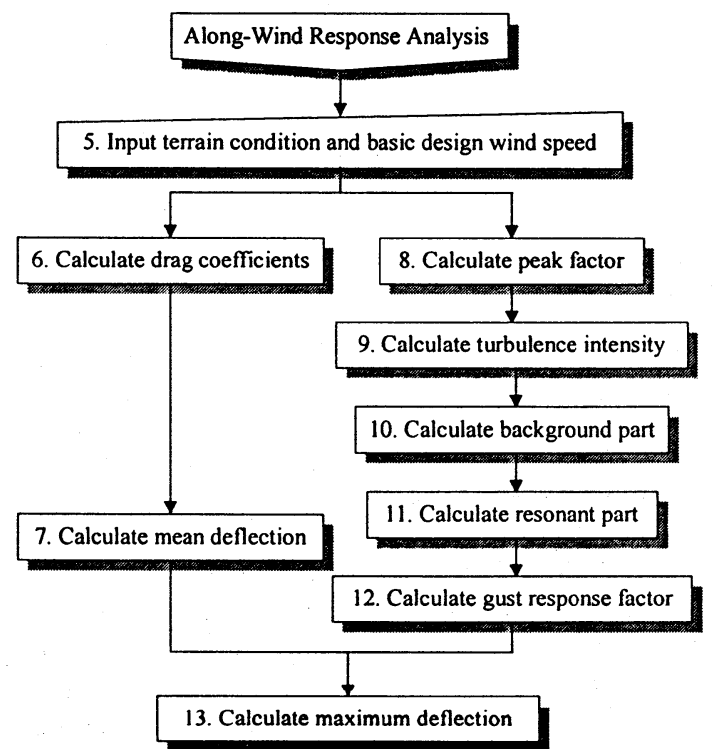

Fig. 2. Along-Wind Response Analysis Procedure in Fig. 1. The basic dimensions of a chimney (e.g., height, diameter, thickness, etc.) need to be established first. These inputs are checked against geometry constraints from ACI code and heuristics. Dynamic characteristics of the structure (e.g., natural frequencies, mode shapes, and general masses, etc.) are then determined using external numerical programs integrated with the system.

- Along-Wind Response Analysis - At this stage, a series of calculations (see Fig. 2) is performed based on the terrain condition and basic design wind speed. The maximum along-wind deflection can be obtained after the calculation of the drag coefficients, peak factor, turbulence intensity and gust response factor. The calculation is founded on the assumptions that high-order vibration modes can be ignored, and quasi-steady theory and strip theory apply to the case.

- Across-Wind Response Analysis - Fig. 3 shows the analysis steps used in the system to calculate the maximum deflections in the first three modes of vibration. The calculation follows the procedures developed by Vickery and coworkers ${ }^{6,7,8)}$.

- Section Design - The preliminary section design of chimneys is based on the above analyses and ACI 307-98 strength method. The process begins with the calculations of

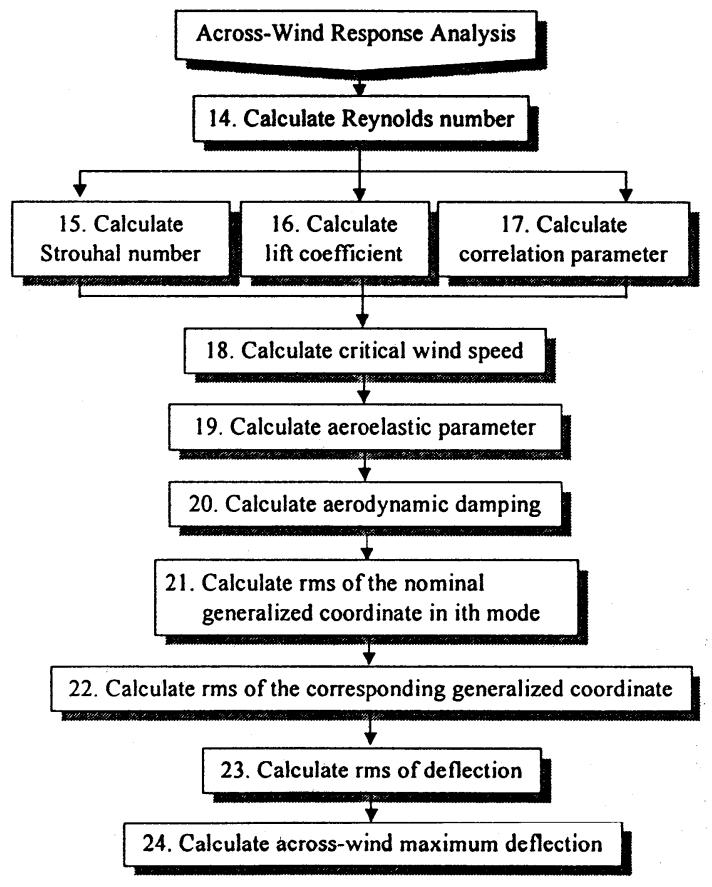

Fig. 3. Across-Wind Response Analysis Procedure 


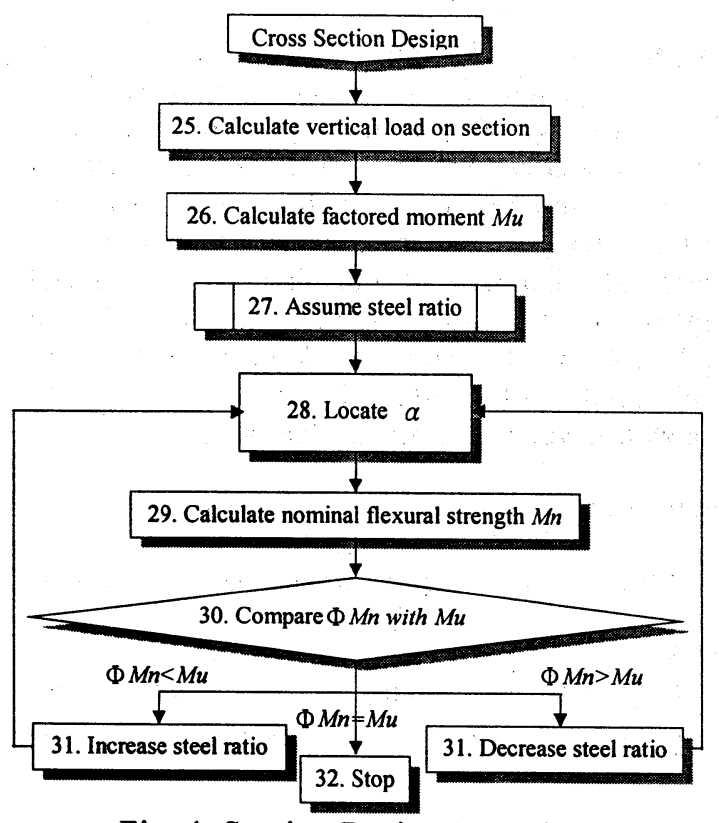

Fig. 4. Section Design Procedure

the factored vertical load and the corresponding factored moment acting on the section. In addition to the basic design wind speed, critical wind speeds corresponding to $1^{\text {st }}, 2^{\text {nd }}$ and $3^{\text {rd }}$ mode are taken into account in the determination of the factored wind forces. This is followed by nominal moment strength calculation. A try-and-error loop is used to find the reinforcement ratio of the section. The design procedure is illustrated in Fig. 4. Currently, the system is limited to vertical reinforcement design. Design for circumferential bending has not been included yet.

\section{SYSTEM IMPLEMENTATION AND KNOWLEDGE REPRESENTATION}

The system was developed in Kappa-PC, an AI software development environment. Kappa-PC was chosen because of its flexible knowledge representation and hybrid reasoning paradigms. Kappa-PC runs under MS Windows 98 or 2000 . The knowledge-based system provides friendly user interfaces, which enable users to communicate with the system easily. Eighteen user interface windows were built using Kappa-PC's image objects. In order to exchange information with other numerical programs (e.g., numerical integration and finite element analysis) under Windows, data exchange routines were developed.

Object-oriented programming is the main methodology used in implementing the system. The knowledge-based system has generic objects and behavior procedures (i.e., classes and methods) defined to encapsulate wind engineering, structural design, structural dynamics and random vibration knowledge. On the other hand, rule-based reasoning is used to process experiential knowledge. For example, the selections of initial structure dimensions and wind force analysis coefficients are carried out using rule-based reasoning.

There are 15 classes and 21 instances in the knowledge base of the system. Fig. 5 shows the hierarchical relations of the objects. The following are brief descriptions of the major object classes in the system:

- Chimney is the physical design object class that contains 27 attributes including user inputs, design variables and design coefficients. It has 19 methods that perform tasks ranging from geometry calculation to external program communication. Chimney can have instances representing different design options and all the instances inherit attributes and methods from their superclass Chimney. Information about a particular chimney is stored at the instance level.

- Analysis is the super class of all the structure loading analysis modules. Wind represents the wind loading analysis module. It is further divided into Along_wind and Across_wind corresponding to the along-wind and across-wind analysis process. There are a total of 72 attributes and 55 methods contained in the classes to encapsulate the analysis knowledge. Three mode shapes are considered in across-wind analysis. Instances under Mode1, Mode 2 and Mode 3 are used to store first, second and third mode analysis results.

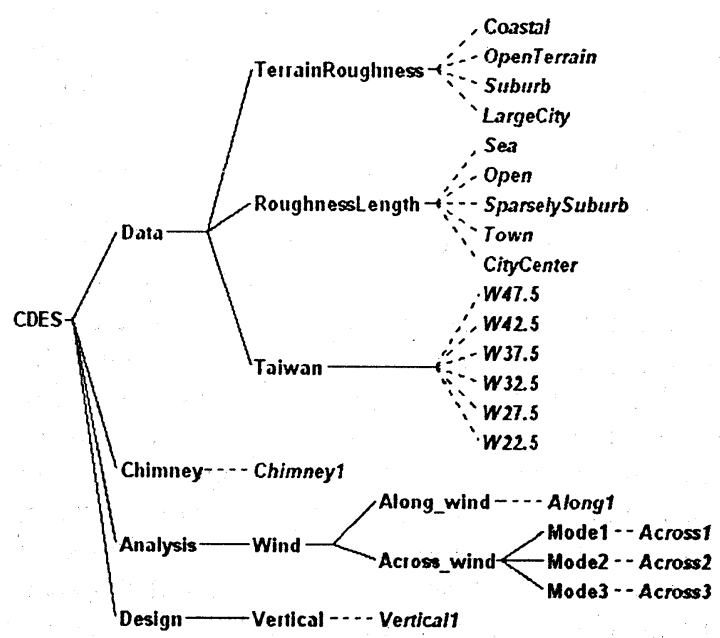

Fig. 5. Object Hierarchy of the System 
- Data is the super class of all the design parameters used in the system. The instances below it are the different analysis and design parameters from codes, specifications, material properties and heuristics. Currently, we have three categories and represented as subclasses under Data, namely, TerrainRoughness, RoughnessLength, and Taiwan. The roughness of terrain and gradient height suggested by ANSI are represented as instances of TerrainRoughness. The roughness length in relation to different ground conditions are represented as instances of RoughnessLength. The instances of Taiwan contain the basic design wind speed of Taiwan. The information in these objects is usually used as facts for rule-based reasoning in the system.

- Design is the super class of the design modules, and Vertical (the only subclass for now) has 36 attributes and 31 methods that used to store the final design results and encapsulate vertical reinforcement design knowledge.

There are 23 forward-chaining and 8 backward-chaining rules in the knowledge base of the system. Rules are used to represent heuristic knowledge, which make the knowledge transparent and easier to maintain. Forward-chaining rules are grouped into two modules, coefficient selection and dimension examination, based on their application area. Backward-chaining rules are used for terrain consultations.

\section{CONCLUSIONS}

The knowledge-based system has been validated using data in literature ${ }^{\text {9). Frequencies }}$ and across-wind responses calculated by the system are very close to the data in the reference. Along-wind responses are always larger than the data in the reference because that the aerodynamic admittance function used in the system is very conservative.

The scope of the system is limited to the design of reinforced concrete chimneys subjected to wind loads. However, it shows that the combination of heuristics and first principle knowledge in such a design framework allows the users to get design suggestions and preliminary design results rapidly. Furthermore, the object-oriented and rule-based representations used to encode the wind engineering knowledge make the system modular and the knowledge explicit, which puts a premium on further development of the system. Grouped chimney design is under consideration.

The basic system framework, analysis and design modules are in place. $\mathrm{AI}$ and expert system techniques will be extended to areas like initial sizing of chimneys, estimation of structural damping, determination of initial reinforcement ratio, suggestion of design modification, etc. More work is carried out to bring this knowledge-based system to the WWW as a web-based teaching and learning tool.

\section{References}

1) B. G. Buchanan and E. H. Shortliffe, "Rule-Based Expert Systems," Addison-Wesley, 1984.

2) M. L. Maher, Ed., "Expert Systems for Civil Engineers: Technology and Application," American Society of Civil Engineers, New York, 1987.

3) M. Arockiasamy, "Expert Systems Applications for Structural, Transportation and Environmental Engineering," CRC Press, 1993.

4) I. D. Tommelein, Ed., "Expert Systems for Civil Engineers: Integration Issues," American Society of Civil Engineers, New York, 1996.

5) Ahsan Kareem and Robert H. Allen, "Development of Knowledge-Based Systems in Wind Engineering," Journal of Wind Engineering and Industrial Aerodynamics, Vol. 36, 1990.

6) B. J. Vickery and R. I. Basu, "Across-Wind Vibration of Structures of Circular Cross-Section, Part 1, Development of a Two-Dimensional Model for Two-Dimension Conditions," Journal of Wind Engineering and Industrial Aerodynamics, Vol. 12, pp. 49-73, 1983.

7) B. J. Vickery and R. I. Basu, "Across-Wind Vibration of Structures of Circular Cross-Section, Part 2, Development of a Mathematical Model for Full Scale Application," Journal of Wind Engineering and Industrial Aerodynamics, Vol. 12, pp. 75-97, 1983.

8) R. I. Basu, Across-Wind Response of Slender Structures of Circular Cross Section to Atmospheric Turbulence, Vol. 1, Research Report BLWT-2-1983, University of Western Ontario, Faculty of Engineering Science, London, Ontario, Canada, 1983.

9) William H. Melbourne, John C. K. Cheung and Charles R. Goddard, "Response to Wind Action of 265-m Mount Isa Stack," Journal of Structural Division, ASCE, Vol. 109, No. 11, 1983.

key words : expert system, chimney, aeroelastic, aerodynamic, random vibration, rule-based reasoning, object-oriented programming 


\title{
Comparisons of peak pressure coefficients for wind load on cladding in national and international standards
}

\author{
Ryuichro Yoshie ${ }^{\text {1), }}$ Morimasa Watakabe ${ }^{2)}$, Yasuo Okuda ${ }^{3)}$, Hisashi Okada ${ }^{3)}$ \\ 1) Technical Research Institute of Maeda Corp., 1576-1 Tsukinowa Namekawa Hiki Saitama 355-0813, Japan \\ 2) Technical Research Institute, Toda Corp., Ibaraki 300-2622, Japan \\ 3) Building Research Institute, Ministry of Construction, Tsukuba 305-0802, Japan
}

\section{INTORODUCTION}

This paper reviews the provisions of wind load on cladding in major national and international standards and compares the peak pressure coefficients between the standards. The basic concepts of the provisions in the standards are similar in the following respects.

- A reference or a design velocity pressure is determined by a basic wind speed and a exposure factor which represents the vertical wind velocity profile for various terrain types.

-External peak pressures and internal peak pressures are evaluated individually and the algebraic combinations of them are regarded as the design wind load on cladding on the assumption that the external peak pressures act simultaneously with the internal peak pressures.

However, the peak pressure coefficients aren't directly comparable because there are differences in averaging time of basic wind speeds and reference heights of the velocity pressure between the standards. Therefore, we adjusted these original pressure coefficients to those of the unified averaging time and reference height. The adjusted external peak pressure coefficients of flat roof, gabled roof, shed roof, barrel roof, building wall and the internal peak pressure coefficients in the standards were compared.

In this abstract, the adjusted external peak pressure coefficients of high-rise building, gabled roof and the internal peak pressure coefficients in the following seven standards are described.

- ISO4354 Wind actions on Structures (1997)

-ENV1991-2-4 Eurocode1 : Basis of design and actions on structures -Part2-4: Actions on structures - Wind actions(1995)

-ASCE STANDARD ANSI/ASCE7-95 Minimum Design Loads for Building and other Structures (1996)

-Australian Standard AS 1170.2 SAA Loading Code part 2: Wind Loads (1989)

- National Building Code of Canada Part 4 Structural Design (1990)

- Swiss Standard Actions on structures (1989)

- Building Standard Law of Japan (2000)

\section{OUTLINE OF WIND LOAD PROVISIONS FOR CLADDING}

Table 1 summarizes the format for the calculation of design wind load on cladding in the standards. As shown in this table, the averaging time of basic wind speeds and the reference heights of the velocity pressure vary with the standards. Furthermore, there are some differences in expression ways of the peak pressure coefficients between the standards. In some standards, the peak pressure coefficients are directly given, whereas in other standards, they are given in the form of the multiplication of mean pressure coefficient and gust factor or more other factors.

Refer to each standard or the reference [1] for more detailed information.

\section{COURSE OF COMPARISON}

The adjusted peak pressure coefficients were calculated by the following procedures.

The pressure calculation formula specified in each standard was rewritten as follows.

$$
w=q_{h} \hat{C}_{P}=q_{h}^{*} K_{1} K_{2} \hat{C}_{P}=q_{h}^{*} \hat{C}_{P}^{*}
$$

where $q_{h}$ is the original reference velocity pressure, $\hat{C}_{P}$ is the original peak pressure coefficient, $q_{h}^{*}$ is the reference velocity pressure of which reference height is mid height of the roof and averaging time is $10 \mathrm{~min}, K_{1}$ is adjustment factor attributed to the difference in averaging times of the basic wind speed, $K_{2}$ is adjustment factor attributed to the difference in reference heights of the velocity pressure, and $K_{1} K_{2} \hat{C}_{P}$ or $\hat{C}_{P}^{*}$ is the adjusted peak pressure coefficient.

The adjustment factor $K_{1}$ was obtained from the ASCE7-95 Commentary Fig.C6-1. According to the Figure, $V_{3 \text { sec }}=1.425 \mathrm{~V}_{10 \mathrm{~min}}, \mathrm{~V}_{\text {lhar }}=0.935 \mathrm{~V}_{10 \mathrm{~min}}$. The adjustment factor $K_{2}$ was calculated using the exposure factor over open terrain in each standard.

The area subject to wind pressure was assumed to be $1 \mathrm{~m}^{2}$.

Thus, the peak pressure coefficients under the same conditions were obtained. 


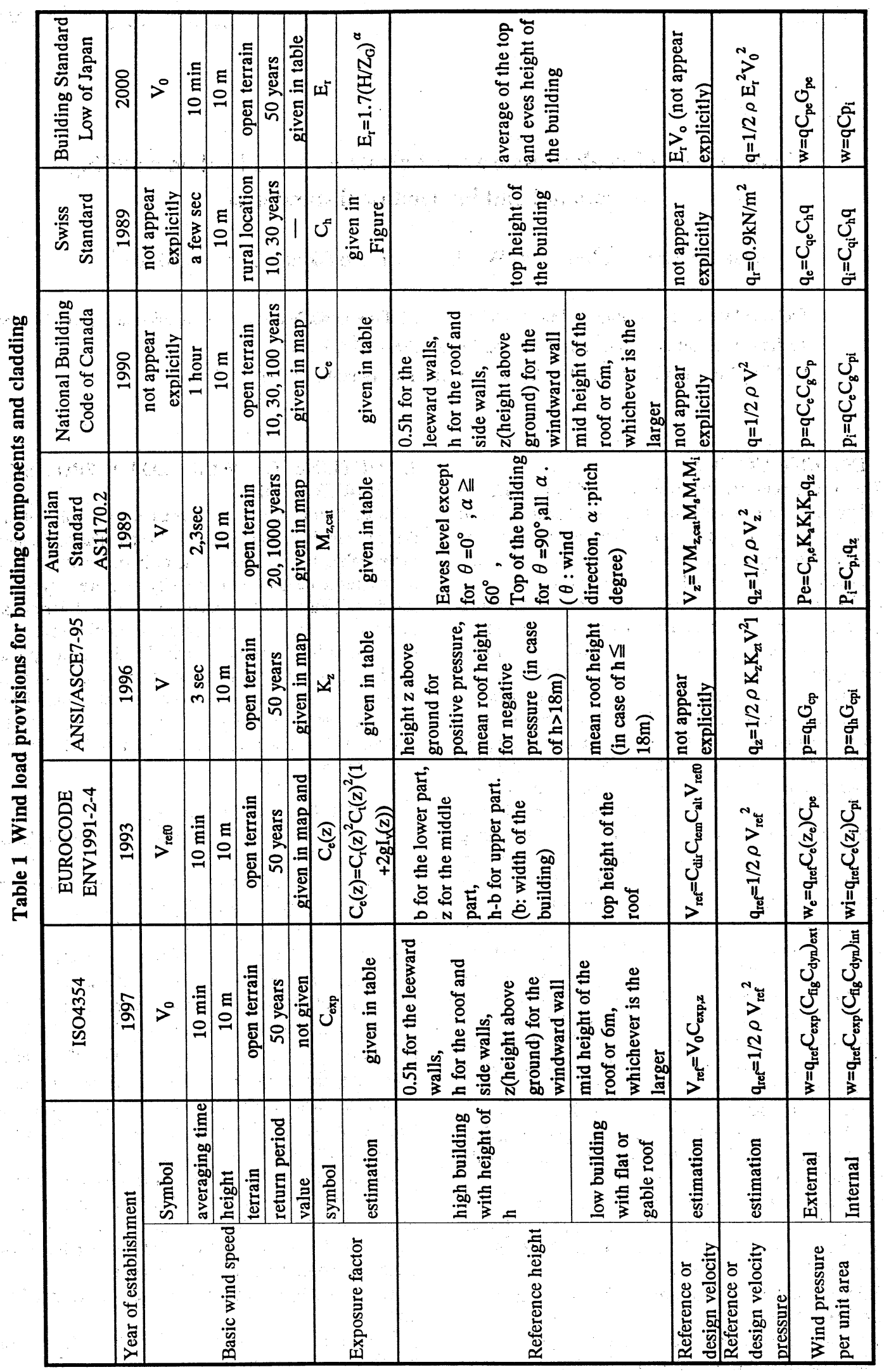




\section{RESULT OF COMPARISON}

\subsection{High-rise building}

Fig.1 shows the shape and size of a high-rise building used for the comparison. The shape is a square cylinder with aspect ratio of 2.0.

Fig.2 indicates the adjusted external peak pressure coefficients $\hat{C}_{P e}^{*}$ on the windward wall of the building. The positive peak pressure coefficients increase with the height above the ground other than the Eurocode. The values upper windward wall are between 1.7 and 2.0.

The negative peak pressure coefficients on sidewall and leeward wall are shown in Table 2 . The values on the sidewall apart from the corners are around -2.0 in almost all standards. ISO gives strongest value of -2.5 in this area, which is attributed to the fact that the pressure coefficients of ISO is cited from the National Building code of Canada not adjusting the difference in the averaging time of the basic wind speed. The negative peak pressure coefficients at the corners considerably vary with the standards from -2.18 (Canada) to -4.04 (Swiss). In all standards, the negative peak pressure coefficients on the leeward wall are around -1.0 except the Eurocode's -0.6. The differences in the peak pressure coefficients of the high-rise building between standards are smaller than those of the gabled roof, which will be shown in the next section.

\subsection{Gabled roof}

Fig. 3 shows the adjusted external negative peak pressure coefficients $\hat{C}_{P e}^{*}$ for a gabled roof with pitch angle $\alpha=30^{\circ}$. The largest magnitude negative peak pressure coefficients in some wind directions are shown in the figures. (The larger one between $0^{\circ}$ and $90^{\circ}$ in Eurocode and AS1170.2, the largest one among $0^{\circ}, 15^{\circ}, 45^{\circ}$ and $90^{\circ}$ in Swiss Standard). ISO, ASCE and NBC have different pressure coefficients between $10^{\circ}<\alpha<30^{\circ}$ and $30^{\circ}<\alpha<45^{\circ}$, so the averages of them are indicated in the figures.

There are significant differences in both pressure coefficients and the ways of area division between the standards. The ranges of the negative peak pressure coefficients are as follows.

-Intersection area of ridge and gable:

$$
-2.68 \text { (Swiss) -4.98 (ASCE) }
$$

-Intersection area of eaves and gable:

$$
-2.68 \text { (Swiss) - } 4.98 \text { (ASCE) }
$$

-ridge apart from the corner:

$$
-1.0 \text { (Euro) -3.35 (ASCE) }
$$

-gable apart from the corner:

$$
-2.27 \text { (Canada) -3.87 (Australia) }
$$

-eaves apart from the corner:

$$
-1.79 \text { (Canada) -3.35 (ASCE) }
$$

-Area except the above (center area of the roof):

$$
-1.0 \text { (Euro) } \sim-2.5 \text { (Japan) }
$$

\subsection{Internal peak pressure coefficient}

This section focuses on the comparison of the internal peak pressure coefficients on claddings in the standards. A building with flat roof shown in Fig.4 were used for the comparison. Fig.5 (a) shows the adjusted internal peak

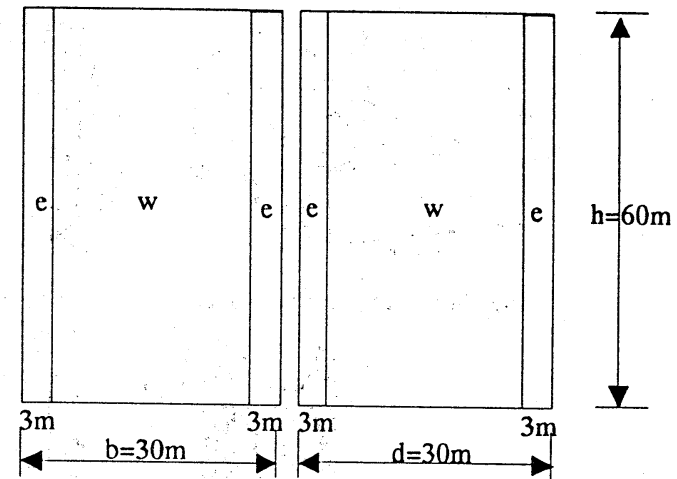

Fig.1 Elevation of a high-rise building

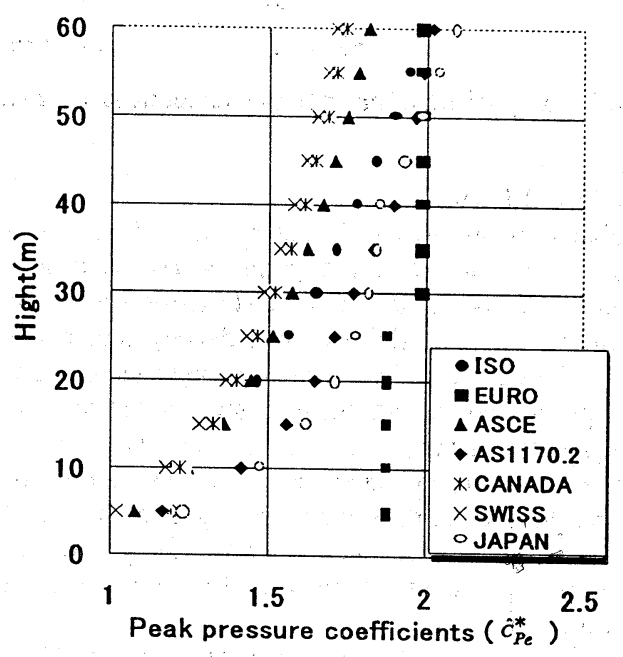

Fig.2 Comparison of adjusted external peak pressure coefficients $\hat{c}_{P e}^{*}$ for high-rise building

Table 2 Comparison of the adjusted external peak pressure coefficients

\begin{tabular}{|c|c|c|c|}
\hline & \multicolumn{2}{|c|}{ Sidewall } & \multirow{2}{*}{ Leeward wall } \\
\cline { 2 - 4 } & $\mathrm{w}$ & $\mathrm{e}$ & \\
\hline \hline ISO & -2.5 & -2.5 & -1.03 \\
\hline EURO & -1.99 & -2.59 & -0.6 \\
\hline ASCE & -1.81 & -3.63 & - \\
\hline AS1170.2 & -1.95 & -3.9 & -1.0 \\
\hline CANADA & -2.18 & -2.18 & -0.95 \\
\hline SWISS & -2.02 & -4.04 & -1.01 \\
\hline JAPAN & -2.4 & -3.0 & - \\
\hline
\end{tabular}

pressure coefficients for walls with uniformly distributed openings or with small openings. Fig. 5 (b) shows those for the windward wall with predominant openings.

For the walls with uniformly distributed openings or with small openings, ISO, AS1170.2, Canada and Japan give values between -0.8 and 0.0 , while ASCE and Swiss give values between -0.3 and 0.3 . For the windward wall with predominant openings, all the standards except Canada with category 3 specify the positive internal peak pressure coefficients which are around $0.9 \sim 1.9$. 


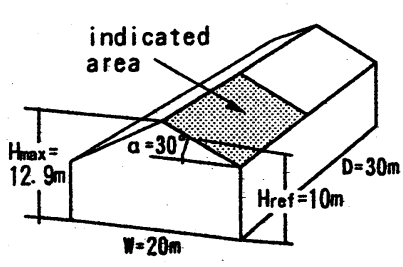

(a) Shape and dimensions

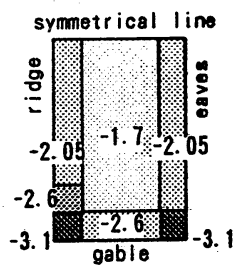

(b) 150

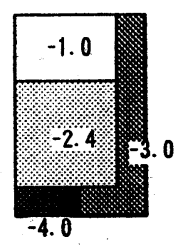

(c) EURO

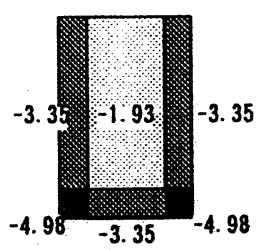

(d) ASCE

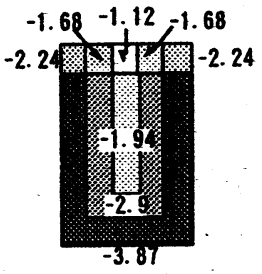

(e) AS1170.2

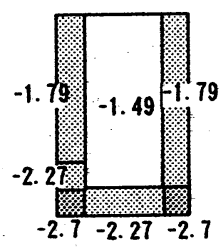

(f) CANADA

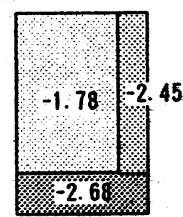

(g) SWISS

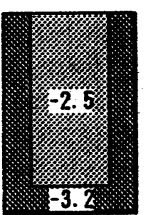

(h) JAPAN

Fig.3 Comparison of adjusted external negative peak pressure coefficients $\hat{C}_{P e}^{*}$ for gabled roof (1/4 area)

\section{CONCLUSION}

We've summarized the format for the calculation of design wind load on cladding in various standards. Although the basic concepts of the standards are similar, the peak pressure coefficients aren't directly comparable because there are differences in averaging time of basic wind speeds and the reference heights of the velocity pressure between the standards. Therefore, we adjusted these original pressure coefficients to those under the same conditions, i.e., the same averaging time (10 $\mathrm{min})$ of basic wind speed, the same reference height for the velocity pressure and the same area $\left(1 \mathrm{~m}^{2}\right)$ subject to the wind pressure.

It has become clear that there are significant differences in the adjusted peak pressure coefficients especially for the gabled roof and the internal pressure with predominant openings.

\section{ACKNOWLEDGMENT}

This research was conducted by 'Pressure Coefficient Committee' that consists of universities, ministry of construction, consultant companies and construction companies in Japan. Professor Takeshi Ohkuma was the chief examiner of the committee.

\section{Reference}

1) J.D.Holmes and K.C.S.Kwok: A comparison of the wind load provisions in some major national and international standards, $1^{\text {st }}$ International Codification workshop for wind loads, Bochum Sept. 2000.

Key word: Standard, Code, External peak pressure coefficient, Internal peak pressure coefficient, Cladding

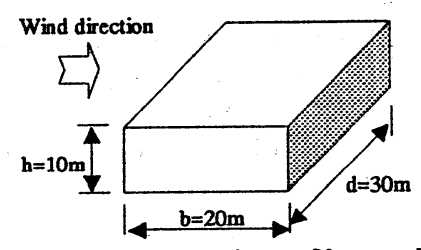

Fig.4 Building for comparison of internal pressure

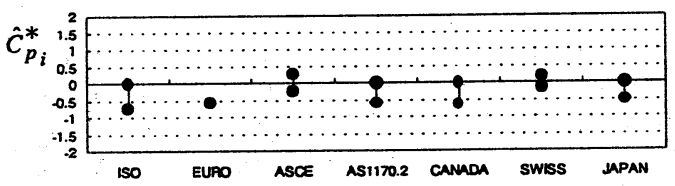

【ISO】 Building without large openings, and only small openings of less than $0.1 \%$ of total area.

[EURO] A homogeneous distribution of openings for a nearly square building. [ASCE] All buildings except listed above.

[AS1170.2】 All walls equally permeable or openings of equal area on all walls.

【CANADA】 Buildings without large or siguificant openings, but having small uniformly distribute openings. (accumulating to less than $0.1 \%$ of total surface area)

【SWISS】All walls with predominant openings(pp.88,Table37in SWISS Standard) 【JAPAN】 $\hat{c}_{P i}^{*}=0$ or -0.5

(a) Walls with uniformly distributed or small openings

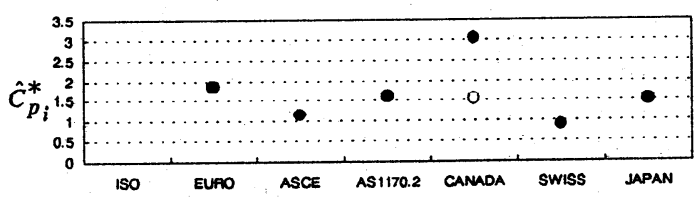

[ISO】 The values of Cfig $>0$ are not given for dominant openings

[EURO] Opening ratio $=0.0$

[ASCE] The positive value of "partially enclosed buildings"

【AS11702) Dominant openings on windward wall

(open windward area)/(total open area of other walls and roofs) $>6.0$ (Cpi=Cpe=0.8)

【CANADA】 Buildings with large or significant openings (OCategory 3 )

Buildings in which background leakage may not be uniformly distributed (OCategory 2)

【SWISS】 Windward wall with a predominant opening.

【JAPAN】 $\hat{C}_{P i}^{*}=1.5$

(b) Windward wall with predominant openings

Fig.5 Comparison of internal peak pressure coefficient 


\title{
Wind Load Provisions of the New Building Code and Building Control System in Japan
}

\author{
Hisashi Okada ${ }^{1)}$, Yasuo Okuda ${ }^{1)}$ and Hitomitsu Kikitsu ${ }^{\text {l) }}$ \\ I) Building Research Institute, Tsukuba 305-0802, Japan
}

\section{INTRODUCTION}

This paper describes wind load provisions of the new Japanese Building Code. The new provisions are composed of the Building Standard Law, the Building Standard Law Enforcement Order, etc. The Building Standard Law, in which objectives of the code, definitions of terms, fundamental concepts and so on were described, was revised in 1998. The revision was a performance-based regulation. Following the revision, technical regulations such as load provisions, structural calculation provisions, etc. were reformed in 2000. They are reflected in the Building Standard Law Enforcement Orders (cabinet orders), the Building Standard Law Enforcement Regulations (Ministry of Construction orders) and Notifications of Ministry of Construction. The revision on wind load provisions was drastic based on AIJ recommendation ${ }^{1)}$. In this paper, major works that were carried out for the revision are presented. In addition, outline of the legal building control system in Japan is presented. This should help us to understand better on the role of the Building Code in Japan.

\section{BUILDING CONTROL SYSTEM IN JAPAN}

The legal procedure at the time of a building construction is described in this section. When a building is to be constructed, the building owner has to submit the plan to regional government before the construction work begins and receive a confirmation whether the plan is lawful to the building code. This rule is applied to all buildings in city planning areas and areas designated by local governors. Timber buildings having 3 stories or more and area $500 \mathrm{~m}^{2}$ or more, reinforced concrete and steel buildings having 2 stories or more and area $200 \mathrm{~m}^{2}$ or more are also subjected to this rule, even though they are outside of the upper mentioned area. There are few exceptions because the area outside of city planning is very limited. The number of new buildings that are applied with this rule in Japan is about $1,100,000$ in a year.

The owner has to show the structural safety of the building to external forces and loads, etc. in the documents of the plan. This is done using structural calculations and specifications prescribed in the code.

\section{NEW WIND LOAD PROVISION}

The radical revisions on the wind load provisions were carried out for the new building code. The revisions were based on AIJ recommendation. The main revisions are on levels of load, clear separation of loads for design of structural frames and design of external building components, introduction of exposure factor and gust effect factor.

\section{(1) Level of wind load}

In the old provisions, wind load level was based on a record at Muroto promontory in a historical huge typhoon, "Muroto" in 1934. There are a lot of data at present, which can give us reliable estimation of the expected value of wind speed through statistical analysis. Utilizing this result, Datum wind speed was prescribed on 50 years return period value in each place in Japan in the new provisions. Datum wind speed was defined as the 10 minute average wind speed at $10 \mathrm{~m}$ height above the ground over the flat open terrain. Taking the uncertainty of typhoons into consideration, the minimum wind speed for datum wind speed was set. The result ranges from 30 to $46 \mathrm{~m} / \mathrm{s}$. A map for the datum wind speed is shown in figure 1.

Design wind speeds were prescribed as 1.0 and $\sqrt{1.6}$ times of datum wind speed for no damage and no collapse design criteria respectively. They are corresponding to return periods of 50 years and 500 years respectively. 


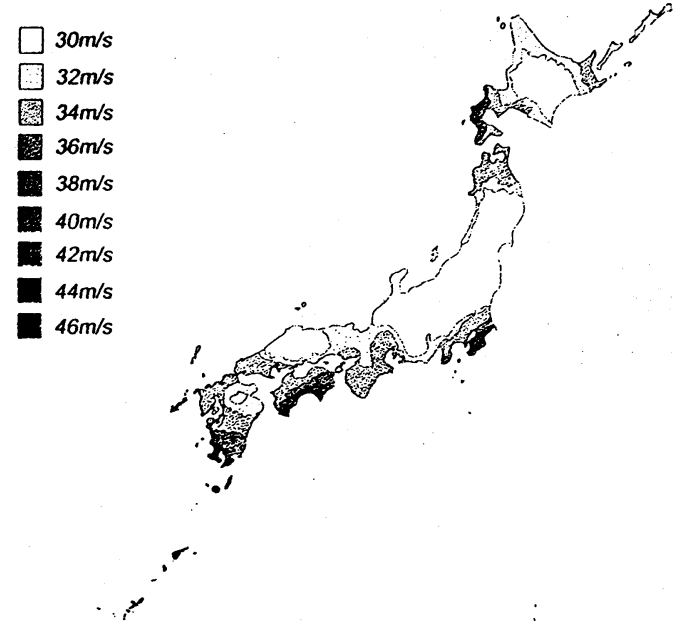

Figure 1 Map of datum wind speed

(2) Load estimation formula

Wind loads for no damage design are given by the following formulas. The formula for structural frames is

$$
W_{f}=0.6 E_{r}^{2} G_{f} V_{o}^{2} C_{f}
$$

where, $W_{f}=$ wind load $\left(\mathrm{N} / \mathrm{m}^{2}\right), E_{r}$ =vertical distribution coefficient for mean wind speed, $G_{f}=$ gust effect factor, $V_{0}=$ datum wind speed $(\mathrm{m} / \mathrm{s})$ and $C_{f}=$ wind force coefficient.

While the formula for external building components is

$$
W_{c}=\bar{q} \cdot \hat{C}_{f}
$$

where, $W_{c}=$ wind load $\left(N / m^{2}\right), \bar{q}=$ mean velocity pressure $=0.6 E_{r}{ }^{2} V_{o}^{2}$ and $\hat{C}_{f}$ =peak wind force coefficient.

\section{(3) Category for exposure factor}

Terrain categories are defined with descriptive expressions and/or photographs showing the typical examples in AIJ recommendation as well as other Standards ${ }^{2,3}$. The definition was considered to have a possibility of creating misunderstand. Hence, a clear definition from the viewpoint of administrative building control was required, which is developed as follows.

The terrain categories are regulated with considerations whether the site is inside the city planning area, what the building height and the distance from sea front or lakefront are. Figure 2 shows diagrammatically the categories.

The area of Category I is designated in the area of Category II, and the area of Category IV is designated in III by regional governments.

In AIJ recommendation, Category $\mathrm{V}$ with heavily concentrated tall buildings is categorized. But this was not categorized in the provisions because it was determined not necessary from the viewpoint of building control.

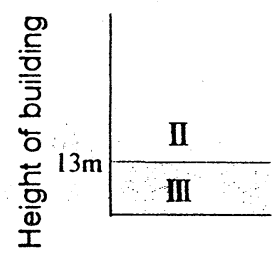

(a) Outside of city planning area

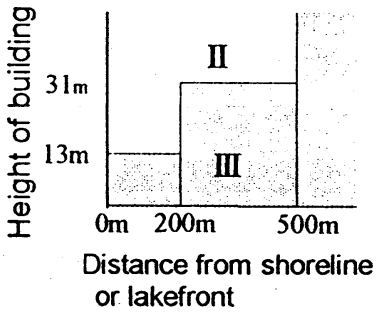

(b) Inside of city planning area
Figure 2 Categories of exposure factor

(4) Vertical distribution co. for mean wind speed

$E_{r}$ or vertical distribution coefficient for mean wind speed is given with the following equation.

$$
\begin{aligned}
E r & =1.7\left(\frac{Z_{b}}{Z_{G}}\right)^{\alpha} \quad H \leq Z_{b} \\
& =1.7\left(\frac{H}{Z_{G}}\right)^{\alpha} \quad H>Z_{b}
\end{aligned}
$$

where, $H=$ mean height of roof, and the other parameters are shown in table 1. Figure 3 shows the figure of $E_{r}$.

Table 1 Parameters of $E_{r}$

\begin{tabular}{|c|c|c|c|}
\hline $\begin{array}{c}\text { Terrain } \\
\text { category }\end{array}$ & $Z_{b}(m)$ & $Z_{G}(m)$ & $\alpha$ \\
\hline I & 5 & 250 & 0.10 \\
\hline II & 5 & 350 & 0.15 \\
\hline III & 5 & 450 & 0.20 \\
\hline IV & 10 & 550 & 0.27 \\
\hline
\end{tabular}

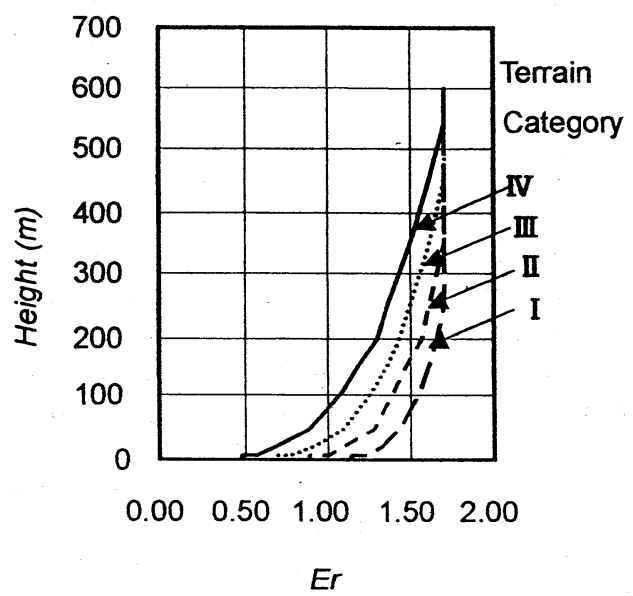

Figure $3 E_{r}$ (=Vertical distribution coefficient for mean wind speed) 


\section{(5) Gust effect factor}

Gust effect factor is used to convert the 10-minute average velocity pressure to instantaneous wind force. Dynamic effect such as resonance between the dynamic behavior of structural frame and the wind load fluctuation is taken into account with the gust factor. Table 2 shows gust effect factors prescribed in the provisions. The gust effect factor was derived with the detailed procedure II of AIJ recommendation, assuming the following values;

Datum wind speed $; 35 \mathrm{~m} / \mathrm{s}$

Building; Aspect ratio $=1,2$ and 4

Natural frequency; $40 / H_{T}(\mathrm{~Hz})$, where, $H_{T}=$ building height

Damping coefficient $=0.02$

The provisions prescribe wind tunnel tests or actual measurements to determine the gust effect factor.

Table 2 Gust effect factor

\begin{tabular}{|l|l|l|l|}
\hline \multirow{2}{*}{$\begin{array}{l}\text { Terrain } \\
\text { category }\end{array}$} & \multicolumn{3}{|l|}{ Mean height of roof } \\
\cline { 2 - 2 } & $H \leq 10 \mathrm{~m}$ & $10<H<40 \mathrm{~m}$ & $40 \mathrm{~m} \leq H$ \\
\hline I & 2.0 & & \\
\hline II & 2.2 & due to linear & 2.8 \\
III & 2.5 & & 2.0 \\
\hline interpolation & 2.1 \\
& 3.1 & 2.3 \\
\hline
\end{tabular}

(6)Wind Force coefficient

Wind force coefficient for structural frame is defined as follows.

$$
C_{f}=C_{p e}-C_{p i}
$$

where, $C_{p e}=$ external wind pressure coefficient, $C_{p i}=$ internal wind pressure coefficient.

External wind pressure coefficients for the following shaped buildings and structures are shown in the provisions. They are closed buildings with pitched roof, flat roof, mono-slope roof, arched roof, multi span pitched roof and multi span saw-tooth roof, unenclosed buildings with pitched roof, free roofs of pitched roof and wing type roof, lattice structure, netlike structure and cylindrical structure. Figure 4 shows the external wind pressure coefficients of closed building having flat roof and pitched roof as the examples. " $k$ " in figure 4 is defined as follows;

$$
\text { in case of } H \leq Z_{b}, \quad k_{z}=1.0
$$

in case of $H>Z_{b}$,

$$
\begin{array}{ll}
Z \leq Z_{b}, & k_{z}=\left(\frac{Z_{b}}{H}\right)^{2 \alpha} \\
Z>Z_{b}, & k_{z}=\left(\frac{Z}{H}\right)^{2 \alpha}
\end{array}
$$

" $a$ " is the smaller one between the smaller dimension of building plan and 2 times of the building height. Table 4 shows internal pressure coefficients prescribed in the provisions. Wind tunnel tests are available to obtain external and internal pressure coefficients.

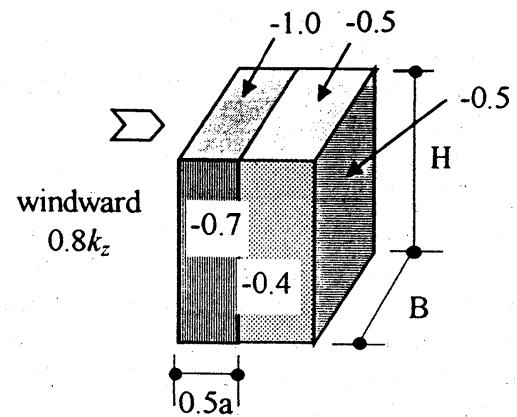

(a) flat roof rectangular building

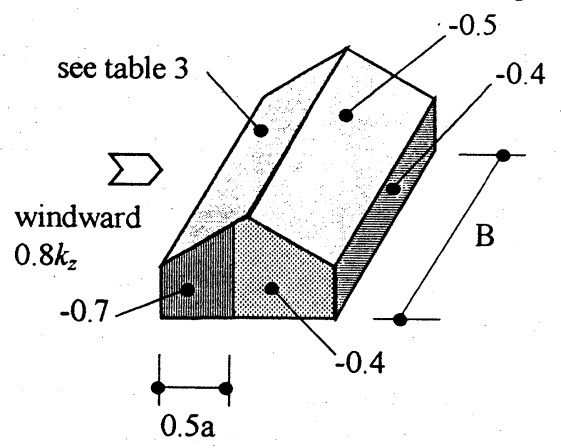

(b) pitched roof rectangular building

Figure 4 External wind pressure coefficient for closed type building

Table 3 External pressure coefficient for windward roof of pitched roof

\begin{tabular}{|c|c|c|}
\hline roof pitch & plus coefficient & minus coefficient \\
\hline less than $10^{\circ}$ & - & -1.0 \\
\hline $10^{\circ}$ & 0 & -1.0 \\
\hline $30^{\circ}$ & 0.2 & -0.3 \\
\hline $45^{\circ}$ & 0.4 & 0 \\
\hline $90^{\circ}$ & 0.8 & - \\
\hline
\end{tabular}

Liner interpolation may be used for the roof pitch shown above

Table 4 Internal wind pressure coefficient

\begin{tabular}{|l|c|c|}
\hline \multirow{2}{*}{$\begin{array}{l}\text { Closed } \\
\text { building }\end{array}$} & \multicolumn{2}{|c|}{ Unenclosed building } \\
\cline { 2 - 3 } & Open in windward & Open in leeward \\
\hline 0 and -0.2 & 0.6 & -0.4 \\
\hline
\end{tabular}

\section{(7)Peak wind force coefficient}

Peak wind force coefficients are given by the following equation.

$$
\hat{C}_{f}=\hat{C}_{p e}-\hat{C}_{p i}
$$

where, $\hat{C}_{p e}=$ peak external pressure coefficient, $\hat{C}_{p i}=$ peak internal pressure coefficient.

Here, attention should be given to the peak internal pressure coefficient. Note that this is not the one to define the real peak internal pressure but the 
contribution of internal pressure to the maximum instantaneous wind forces.

Wind tunnel tests are also available to determine the peak wind force coefficients.

External peak pressure coefficients are given by the products of $C_{p e}$ and $G_{p e}$ when they are positive. But in case that they are negative, they are given by external peak pressure coefficients themselves. Tables 5 and 6 show the $C_{p e}$ and $G_{p e}$ for pitched roofs, mono-slope roofs and multi span saw tooth roofs. Table 7 shows the negative peak external pressure coefficients for pitched roofs. Table 8 shows the peak internal pressure coefficients.

Table 5 Positive $C_{p e}$ for pitched roof, mono-slope roof and multi span saw tooth roof

\begin{tabular}{|c|c|c|c|c|}
\hline roof pitch & $10^{\circ}$ & $30^{\circ}$ & $45^{\circ}$ & $90^{\circ}$ \\
\hline$C_{p e}$ & 0 & 0.2 & 0.4 & 0.8 \\
\hline
\end{tabular}

Table $6 G_{p e}$ for pitched roof, mono-slope roof and multi span saw tooth roof for positive $C_{p e}$.

\begin{tabular}{|c|c|c|c|}
\hline \multirow{2}{*}{$\begin{array}{c}\text { Terrain } \\
\text { category }\end{array}$} & \multicolumn{3}{|c|}{ Mean height of roof } \\
\cline { 2 - 3 } & $\mathrm{H} \leq 5 \mathrm{~m}$ & $5<\mathrm{H}<40 \mathrm{~m}$ & $40 \mathrm{~m} \leq \mathrm{H}$ \\
\hline I & 2.2 & due to linear & 1.9 \\
\hline II & 2.6 & interpolation & 2.1 \\
& 3.1 & & 2.3 \\
\hline III and IV & 3.1 &
\end{tabular}

Table 7 Negative peak external pressure coefficient for pitched roof, mono-slope roof and multi span saw tooth roof

\begin{tabular}{|c|c|c|c|}
\hline \multirow{2}{*}{ Part } & \multicolumn{3}{|c|}{ roof pitch } \\
\cline { 2 - 4 } & $\leq 10^{\circ}$ & $20^{\circ}$ & $\geq 30^{\circ}$ \\
\hline A & -2.5 & -2.5 & -2.5 \\
\hline B & -3.2 & -3.2 & -3.2 \\
\hline C & -4.3 & -3.2 & -3.2 \\
\hline D & -3.2 & -5.4 & -3.2 \\
\hline
\end{tabular}

Part A, B, C and D are indicated in figure 5 .

Liner interpolation may be used for roof pitch other than shown.

" $a$ " in figure 5 is the smaller one between the smaller dimension of building plan and 2 times of the building height.

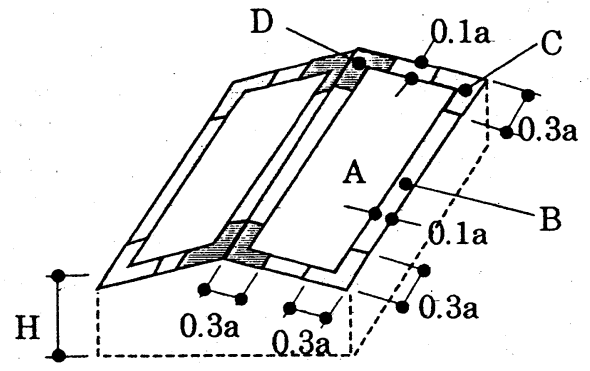

Figure 5 Classification for negative peak external pressure coefficient of pitched roof

Table 8 Peak internal pressure coefficient

\begin{tabular}{|l|l|c|}
\hline Closed & peak external pressure $\geq 0$ & -0.5 \\
\cline { 2 - 3 } building & peak external pressure $<0$ & 0 \\
\hline \multirow{2}{*}{$\begin{array}{l}\text { Unclosed } \\
\text { building }\end{array}$} & open in windward & 1.5 \\
\cline { 2 - 3 } & open in leeward & -1.2 \\
\hline
\end{tabular}

\section{CONCLUSION}

Wind load provisions in the new Japanese Building code were described. Legal building control system in Japan was also presented.

In the wind load provisions, terrain categories were defined clearly from the viewpoint of building control.

The design wind speeds were based on the 50 years return period for no damage design and the 500 years return period for no collapse. These are the 10-minute average wind speeds at $10 \mathrm{~m}$ height above the ground over a flat open terrain.

To develop the new provisions, some simplifications were carried out. As shown in the results, the gust effect factor for structural frame design is defined with terrain category and building height.

Wind load estimation formulas were prescribed for designs of the structural frame and the external building components separately.

Some wind pressure coefficients in the provisions were presented here.

\section{Reference}

1) "AIJ Recommendations for Loads on Buildings" Architectural Institute of Japan, 1996

2) "Australian Standard, AS1170.2-1989, SAA Loading Code Part 2", 1989

3) “ASCE Standard, ANSU/ASCE 7-95”, 1996

Key words:

Building code, Design wind speed, Terrain category Wind pressure coefficient 


\title{
Equivalent Static Lateral Forces on Buildings under Seismic and Wind Effects
}

\author{
By Yin Zhou ${ }^{1)}$, Ahsan Kareem ${ }^{2)}$
1) Postdoctoral Research Associate, Department of Civil Engineering and Geological Sciences, University of Notre Dame, Notre Dame, IN 46556. Email: yzhou@nd.edu \\ 2) Robert M. Moran Professor and Chair, Department of Civil Engineering and Geological Sciences, \\ University of Notre Dame, Notre Dame, IN 46556. Email: kareem@nd.edu
}

\section{INTRODUCTION}

Earthquake ground motions and windstorms are the two major sources of lateral actions on buildings. Due to the stochastic and dynamic features of these actions and building characteristics, random vibration analysis offers a good framework for capturing the interaction between the external actions and the building structures. However, such analysis is usually not an everyday routine of a design office. Instead, equivalent static lateral forces (ESLF) are employed to assess the internal forces generated by the dynamic response to the earthquake-induced ground motions and windstorm actions. Using the ESLF, design engineers can compute the structural response with a simple static analysis. The ESLF ensures the consistency between the static analysis based results and the dynamic structural response. The ESLF plays a very important role in combining information from the earthquake and wind engineering arenas to structural design.

This paper reviews the ESLF in current earthquake and wind engineering practice from a load distribution viewpoint, with particular interest in the ESLF on tall buildings under wind actions.

Generally, the ESLF can be represented by the inertial force when a flexible building is excited by a dynamic action. This is indeed reflected in the current earthquake practice, in which the ESLF is obtained by distributing a base shear to each floor ${ }^{4,11}$. However, in most current international codes and standards on wind loads, the equivalent static wind load (ESWL) is determined by multiplying the mean wind force with a gust loading factor (GLF) ${ }^{1-3,5,7,13-}$ ${ }^{18}$. This results in an ESWL which is significantly different from the inertial force distribution. This paper introduces the development of a new GLF approach ${ }^{21,24}$, including a rigorous description of ESWL ${ }^{9,10,22}$, influence of deficiency in ESWL distribution and procedures in using the new GLF approach in design. A numerical example is also provided to demonstrate the efficacy and convenience of the new GLF model.

\section{EARTHQUAKE FORCES}

Due to a ground motion (Fig. 1a), the corresponding earthquake loads on both rigid and flexible buildings can be obtained (Fig. 1b, 1c):

$$
\widetilde{P}^{E}(z, t)=w(z) \cdot a(t)
$$

where $\tilde{P}^{E}=$ equivalent applied earthquake force; $w$ = dead load; $a$ = ground motion acceleration; $z=$ height; and $t=$ time.
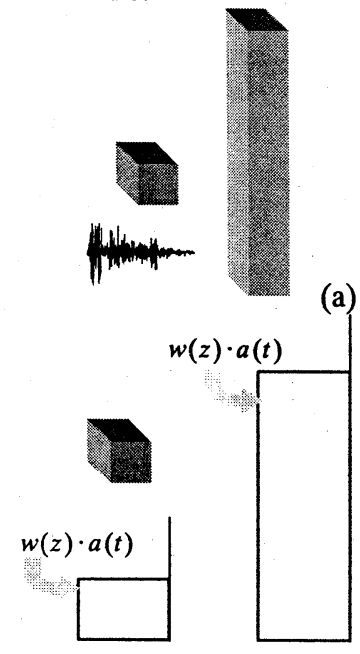

(b)

(c)

Fig. 1 Earthquake actions on buildings 
The equivalent static earthquake force (ESEF) on rigid buildings is controlled by the ground acceleration and can be determined by (Fig. 2a):

$$
\hat{P}^{E}(z)_{\text {rigid }}=w(z) \cdot \hat{a}
$$

in which $\hat{a}=$ peak ground acceleration.

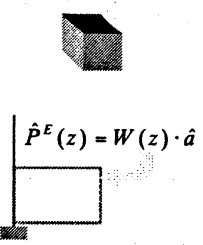

(a)

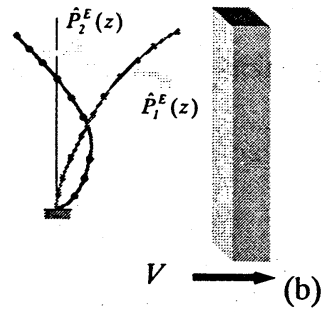

Fig. 2 Equivalent static earthquake forces

For tall buildings which are flexible, the ESEF is controlled by the building inertia and it can be computed by (Fig. $2 b$ ) ${ }^{4,11}$

$$
\hat{P}_{i}^{E}(z)_{\text {flexible }}=\frac{w(z) \varphi_{i}(z)}{\int w(z) \varphi_{i}(z) d z} \cdot V
$$

where $\hat{P}_{i}^{E}=i$ th mode ESEF; $\varphi_{i}=i$ th mode shape, the $1^{\text {st }}$ mode, $\varphi_{1}(z)=(z / H)^{\beta}$; and $V=$ base shear which can be obtained from codes and standards

$$
V=C \cdot W
$$

in which $C=$ spectral acceleration; and $W=$ sum of total dead load of the building.

\section{WIND FORCES IN CURRENT PRACTICE}

The externally applied wind forces on buildings can be expressed separately in mean and fluctuating components (Fig. 3) as

$$
\begin{aligned}
& \bar{P}^{W}(z)=1 / 2 \rho C_{d} B \bar{U}_{H}^{2}(z / H)^{2 \alpha} \\
& p^{W}(z, t)=\rho C_{d} B \bar{U}_{H}(z / H)^{\alpha} u(z, t)
\end{aligned}
$$

where $\rho=$ air density; $C_{d}=$ drag coefficient; $B=$ building width; $\alpha=$ exponent of wind profile; $\bar{U}=$ mean wind speed and $u=$ fluctuating wind speed.

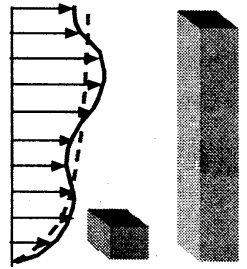

Fig. 3 Externally applied wind forces

In most current international codes and standards, the ESWL is determined by ${ }^{5,1-3,7,13,17}$

$$
\hat{P}^{W}(z)=\bar{P}^{W}(z) \cdot G_{Y}
$$

where $G_{Y}=\hat{Y} / \bar{Y}=$ GLF in terms of displacement, $Y$. In current codes, it is usually expressed by

$$
G_{Y}=1+g r \sqrt{B+R}=1+\sqrt{G_{B}^{2}+G_{R}^{2}}
$$

in which $g=$ peak factor; $r=$ turbulence intensity coefficient; $\boldsymbol{B}=$ background factor; $\boldsymbol{R}=$ resonant factor; and $G_{B}$ and $G_{R}=$ background and resonant GLF, respectively. As shown in Fig. 4, the ESWL and its components follow the mean wind force distribution or a function of $2 \alpha$, which is very much different from the inertial force distribution, which is a function of mode shape exponent, $\beta$ when assuming a uniform dead load distribution.

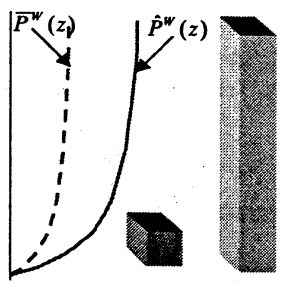

Fig. 4 ESWL in current practice

\section{ACTUAL ESWL ON BUILDINGS}

To examine the effectiveness of the current GLF model, an understanding of the actual ESWL is desired. The dilemma concerns mainly the background component, since the resonant component has been generally understood to be the inertial force.

A convenient and effective approach to evaluate the background ESWL refers to the "load-responsecorrelation" method ${ }^{12}$, which was originally employed to evaluate load distribution on low-rise building. In this method, the wind correlation and influence coefficient function are incorporated to provide the most unfavorable load distribution with regard to the response of interest:

$\hat{P}_{B}(z)=g_{B} Q(z) \sigma_{p}(z)$

$$
\begin{aligned}
& Q(z)=\frac{\int_{0}^{\infty} \int_{0}^{H} \int_{0}^{B} \int_{0}^{\beta} \overline{p\left(z, x_{1}\right) p\left(z_{1}, x_{2}\right)}\left(z_{1}\right) d x_{1} d x_{2} d z_{1} d f}{\left(\int_{0}^{\infty} \int_{0}^{H} \int_{0}^{H} \int_{0}^{B} \int_{0}^{\beta} \overline{p\left(z_{1}, x_{1}\right) p\left(z_{2}, x_{2}\right)}\left(z_{1}\right) i\left(z_{2}\right) d x_{1} d x_{2} d z_{1} d z_{2} d f\right)^{1 / 2} \cdot \sigma_{p}(z)} \\
& \sigma_{p}(z)=\left(\int_{0}^{\infty} \int_{0}^{B} \int_{0}^{B}\left(\rho \bar{U}(z) C_{d}\right)^{2} S_{u}(f) R_{x}\left(x_{1}, x_{2}\right) d x_{1} d x_{2} d f\right)^{1 / 2}
\end{aligned}
$$

where $Q=$ load-response-correlation coefficient; $S_{u}(f)=$ spectrum of fluctuating wind speed; $R=$ wind correlation; and $i=$ influence function.

With the evaluation of the background ESWL component, general procedures for ESWL can be developed for buildings and any other civil structures, both rigid and flexible, by combining the mean and resonant ESWL descriptions ${ }^{9,10,20,22}$.

\section{DEVIATIONS IN LOAD EFFECTS}

Although a parameter analysis shows that the background ESWL in current GLF model usually provide desirable background response estimates 21,22, for the resonant ESWL components (Fig.5a), the apparently different load distributions may lead 


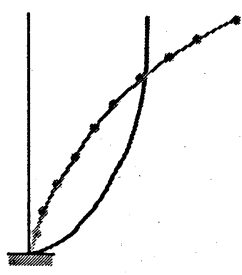

(a)

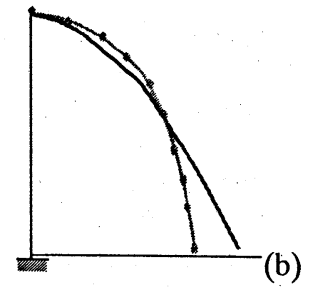

Fig. 5 Comparison of resonant ESWL

to deviations in the load effects (Fig. 5b). Taking the base shear force as an example, as shown in Table 1 , the estimate of resonant base shear component by the current GLF approach may be 1.52 times of that induced by an inertial force, even under the condition that both load patterns lead to the same displacement response, for $\alpha=0.15$ and $\beta=2.0^{22}$.

Table 1: Deviations in resonant base shear force

\begin{tabular}{|l|c|c|c|c|}
\hline$\alpha$ & $\beta=0.5$ & $\beta=1.0$ & $\beta=1.5$ & $\beta=2.0$ \\
\hline 0.15 & 1.04 & 1.18 & 1.35 & 1.52 \\
\hline 0.25 & 1 & 1.11 & 1.25 & 1.4 \\
\hline 0.35 & 0.97 & 1.06 & 1.18 & 1.31 \\
\hline
\end{tabular}

\section{A NEW GLF MODEL}

A new GLF model is developed to overcome this shortcoming. In the new model, the GLF is defined by the base bending moment (BBM) $)^{21,24}$

$$
G_{M}=\hat{M} / \bar{M}
$$

With this new GLF, the mean and background ESWL components remain the same as those in the current model, while the resonant ESWL is obtained by distributing the BBM to each floor

$$
\hat{P}_{R}^{W}(z)=\frac{w(z) \varphi_{1}(z)}{\int_{0}^{H} w(z) \varphi_{1}(z) z d z} \cdot \bar{M} \cdot G_{R}
$$

Several reasons for using BBM rather than the base shear include the numerical equivalence between the BBM GLF and the current GLF, and the insensitivity of the BBM GLF to involved parameters $^{21,23,24}$. The BBM based GLF concept provides a convenient avenue to ensure a smooth transition from the current wind load model to a more realistic dynamic wind load model.

\section{AN EXAMPLE}

Application of the current GLF model and the new GLF model to an example tall building is illustrated in Fig. 6. Relevant information to this building include: $H \times B \times D=200 \times 50 \times 40 \mathrm{~m}$; $f_{1}=0.22 \mathrm{~Hz} ; \beta=1.6$; damping ratio $=0.01$; uniform dead load $w=5.5 \times 10^{5} \mathrm{~kg} / \mathrm{m} ; \bar{U}_{10}=30 \mathrm{~m} / \mathrm{s}$; $\alpha=0.15 ; \sigma_{u} / \bar{U}_{10}=0.2$; and Davenport spectrum.

For this particular example the GLF and its components are $G_{B}=0.65, G_{R}=0.97$ and $G=2.17$, respectively. Since the two GLF models provide different ESWL (Fig. 6), the estimates on windinduced response maybe different. Taking the base shear as an example, the resonant component by the new GLF model is $77 \%$ of that by the current GLF model. Although the mean and background components are the same in the two GLF models, the overall base shear estimate by the current GLF model is $8 \%$ larger than the actual value as shown in Table 2. For base shear force, the current GLF model leads to conservative estimate, while the shear force at the building top will be on the unsafe side as shown in Fig. 6.

Table 2: Apply two GLF Models to base shear

\begin{tabular}{|l|c|c|c|}
\hline & $G_{B}$ & $G_{R}$ & $G$ \\
\hline Current GLF & 0.65 & 0.97 & 2.17 \\
\hline New GLF & $0.65(1.00)$ & $0.75(0.77)$ & $1.99(0.92)$ \\
\hline
\end{tabular}

Items in the parenthesis are ratios between the base shear components by the new GLF model and those by the current GLF model

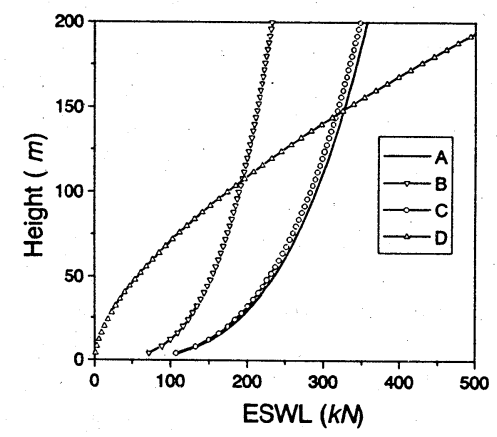

A: Mean; B: Background; C: Resonant by current GLF model; D: Resonant by new GLF model

\section{Fig. 6 ESWL using two GLF models}

\section{CONCLUDING REMARKS}

Under the dynamic earthquake and windstorm actions, flexible buildings may vibrate in their natural modes, resulting in equivalent static lateral forces that follow the inertial force or are a function of the mode shape and dead load distribution. This load pattern is indeed reflected in the current earthquake practice. However, in current wind practice, based on the traditional GLF approach, the ESWL follows the mean wind forces for both rigid and flexible buildings. Usually, this load distribution is very much different from an inertial force pattern and may lead to deviations in response estimates. Care should be exercised when using the traditional GLF to very slender buildings, in which the resonant response is often dominant. A new GLF model is developed to provide a more realistic ESWL on buildings. In this model, the ESWL is obtained by 
distributing the base bending moment to each floor resulting in ESWL distributions as shown in Fig. 7.

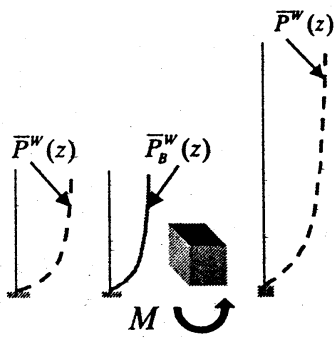

(a) Rigid buildings

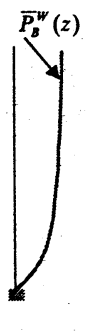

(b) Flexible buildings
Fig. 7 ESWL on buildings

\section{ACKNOWLEDGEMENT}

The authors gratefully acknowledge the partial support from NSF Grants \# CMS 95-03779, CMS 95-22145 and CMS 00-85019 for this study.

\section{References}

1) Architectural Institute of Japan (AIJ) (1996). "Recommendations for Loads on Buildings."

2) ASCE (1999). "Minimum Design Loads for Buildings and Other Structures." ASCE 7-98, ASCE, 1801 Alexander Bell Drive, Reston, Virginia 20191-4400.

3) "Australian Standards: SAA Loading code, Part 2 - wind loads." (1989). AS1170.2-89, Standards Australia.

4) Building Seismic Safety Council (BSSC) (1998), 1997 Edition NEHRP Recommended Provisions for the Development of Seismic Regulations for New Buildings and Other Structures, FEMA 302, developed for the Federal Emergency Management Agency, Washington, D.C.

5) Davenport, A. G. (1967). "Gust loading factors." J. Struct. Div., ASCE, 93(3), 11-34.

6) Davenport, A.G. (1995). "How can we simplify and generalize wind loading?" J. Wind Engrg. Indust. Aerodyn., 54/55, 657-669.

7) Eurocode 1 (1995). "Basis of Design and Actions on Structures - Part 2-4: Actions on structures - Wind actions". European Prestandard ENV 1991-2-4.

8) GBJ9-87 (1990), Chinese loading code, Peking.

9) Holmes, J. D. (1996). "Along-wind response of lattice towers- III. Equivalent load distribution", Engrg. Struct., 18(7), 489-484.

10) Holmes, J. D., and Kasperski, M. (1996). "Effective distributions of fluctuating and dynamic wind loads." Australian Civ./Struct. Engrg., CE38(2, 3, \&4).

11) International Council of Building Officials (1997), Uniform Building Code, Whittier, CA.
12) Kasperski, M., Niemann, H. J. (1992). "The L.R.C. method- a general method of estimating unfavorable wind load distributions for linear and non-linear structures", J. Wind Engrg. Indust. Aerodyn., 41-44, 1753-1763.

13) NRCC (1996). “User's Guide-NBC1995 Structural Commentaries (Part 4)".

14) Simiu, E., and Scanlan, R. (1996). "Wind effects on structures: fundamentals and applications to design." 3rd ed. Wiley \& Sons, Inc., New York.

15) Solari, G. (1993b). "Gust buffeting. II: Dynamic along-wind response." $J$. Struct. Engrg., ASCE, 119(2), 383-397.

16) Solari, G., and Kareem, A. (1998). "On the formulation of ASCE 7-95 gust effect factor." $J$. Wind Engrg. Indust. Aerodyn., 77/78, 673-684.

17) Vellozzi, J., and Cohen, E. (1968). "Gust response factors." J. Struct. Div., ASCE, 94(6), 1295-1313.

18) Vickery, B. J. (1970). "On the reliability of gust loading factors." Proc., a Technical Meeting concerning Wind Loads on Buildings \& Struct., Building Sci. Series 30, National Bureau of Standards, Washington, D.C., 296-312.

19) Vickery, B. J. (1995). "The response of chimneys and tower-like structures to wind loading." A State of the Art in Wind Engrg., Ninth Int. Conf. on Wind Engrg., New Delhi, India, 205-233.

20) Zhou, Y., Gu, M., and Xiang, H. F. (1999a). "Along-wind static equivalent wind loads and response of tall buildings Part I: unfavorable distributions of static equivalent wind loads." $J$. Wind Engrg. Indust. Aerodyn., 79(1 2), 135151.

21) Zhou, Y., Kareem, A., and Gu, M. (1999b). "Gust loading factors for design applications." Proc. of 10th International Conference on Wind Engineering, Copenhagen, Denmark, 169-176.

22) Zhou, Y., Kareem, A., and Gu, M. (2000a). "Equivalent static buffeting wind loads on structures.” J. Struct. Engrg., ASCE, 126(8), 989-992.

23) Zhou, Y., Kareem A. and Gu, M. (2000b). "On the mode shape corrections for wind load effects on tall buildings". J. Engrg. Mech., ASCE, in press.

24) Zhou, Y., and Kareem, A. (2001). "Gust loading factor: a new model." J. Struct. Engrg., ASCE, 127(2), 168-175.

Key words: Wind load; gust loading factor; dynamics; high-rise building; code; earthquake. 


\title{
Along-wind equivalent wind loads and responses on tall buildings
}

\author{
M. Gu and F. Ye \\ State Laboratory for Disaster Reduction in Civil Engineering, Tongji University, Shanghai 200092, China
}

\section{INTRODUCTION}

"Gust loading factor" (GLF) method[1] developed by Davenport has been applied in almost all the current codes of major countries [2-4] for along-wind equivalent wind loads. It has been indicated in [5] that the wind loads by the method can only provide an accurate assessment of the first mode displacement response, but results in less accurate estimation of other response quantities, for example, the base shear force. Zhou et al.[6] proposed a new MGLF method for overcoming the shortcoming of the GLF method through employing a base moment gust loading factor. This method seems to be able to provide more accurate estimations of the equivalent wind loads on buildings. Solari et al.[7] proposed a single coherent formulation that provides compact expressions for estimating the 3D wind-excited responses based on a generalized gust factor approach, but the gust factor and corresponding equivalent load are also based on the principle of "equivalent displacement", as same as that of the GLF method.

In this paper, a more practical method for estimation of along-wind equivalent wind loads on buildings is proposed. The formulas of this method are not relative to the response type and are very simple in form, so they are suitable for code and standard uses. Finally, numerical examples of two representative buildings, one is a low building and the other is a tall one, are shown to demonstrate the precision of the present method.

\section{BASIC ASSUMPTIONS}

The basic assumptions are the same as those in [5] except the following items

(1) The cross-section configuration varies uniformly along the height of the building, that is

$B(z)=B_{o}\left(1-t \frac{z}{H}\right)$ where $B_{0}$ is the building's base width; $\mathrm{H}$ is the height; $\mathrm{t}$ is the taper of the building, $t=\frac{B_{0}-B_{H}}{B_{0}}$, $B_{H}$ is the building's top width.

(2) The mass distribution obeys

$m(z)=m_{0}\left(1-t \frac{z}{H}\right)^{2}$

where $m_{0}$ is the mass per unit length at the base of the building.

(3) The co-relation functions of fluctuating wind take Shiotani's expressions:

$R_{z}\left(z_{1}, z_{2}\right)=\exp \left(-\frac{\left|z_{1}-z_{2}\right|}{60}\right)$
$R_{x}\left(x_{1}, x_{2}\right)=\exp \left(-\frac{\left|x_{1}-x_{2}\right|}{50}\right)$

The functions have been recommended to engineers in Chinese Code $[8,9]$.

(4) The influence function of the building under externally applied or static equivalent loads is

$i(z)=i_{c}\left(\frac{z-h}{H}\right)^{\beta_{0}}$, for $\mathrm{z} \geq \mathrm{h}$;

and $i(z)=0$, for $\mathrm{z}<\mathrm{h}$

where $i_{c}$ and $\beta_{0}$ are constants, and they usually differ for different responses; $h$ is the height at which the responses are to be found, and is hereafter referred to as influence height.

\section{SIMPLIFIED FORMULAE OF ACTUAL STATIC EQUIVALENT WIND LOADS AND LOAD EFFECTS}

The formulas for mean wind loads and the responses are the same as those in [5] and are not be presented here due to the limitation of the space.

3.1 Background equivalent wind loads and effects 
The formula for background equivalent wind load is defined as

$$
P_{B}(z)=\frac{r_{B}}{\bar{r}} \bar{P}(z)=\frac{g_{B} \sigma_{B}}{\bar{r}} \bar{P}(z)
$$

where $r_{B}$ is the background response, namely the background shear force or moment, etc.; $\sigma_{r B}$ is the RMS background response. The background equivalent wind load thus can be rewritten as

$P_{B}(z)=\frac{r_{B}}{\bar{r}} \bar{P}(z)=\rho g_{B} C_{d} \bar{U}_{H} \sigma_{u} B(z)\left(\frac{z}{H}\right)^{2 \alpha} K$

$K=$

$$
\frac{\sqrt{\int_{0}^{H} \int_{0}^{B\left(z z_{1}\right)} \int_{0}^{B\left(z z_{2}\right)} \int_{0}^{2} R_{z} R_{x}\left(\frac{z_{1}}{H}\right)^{\alpha}\left(\frac{z_{2}}{H}\right)^{\alpha} i\left(z_{1}\right) i\left(z_{2}\right) d x_{1} d x, d z_{1} d z_{2}}}{i_{r}^{H} \int_{0}^{H} B(z)\left(\frac{z}{H}\right)^{2 \alpha}\left(\frac{z-h}{H}\right)^{\beta_{0}} d z}
$$

The above equation is essentially the same as that of the background wind load given in [5]. It is relative to $\beta_{0}$, namely the type of response, and has a multiple-integration item, so it is difficult to be adopted for the use in codes and standards. For practical purpose, the simplified formula is given as $P_{B}(z)=C_{B} J_{z B} J_{x B}(1-t z / H)(z / H)^{2 \alpha}$

where

$$
\begin{aligned}
& C_{B}=\rho g_{B} C_{d} \bar{U}_{H} \sigma_{u} \\
& J_{X B}=\frac{B_{0}}{B_{1}} \sqrt{5000\left(\frac{B_{1}}{50}+e^{-B_{1} / 50}-1\right)} \\
& J_{z B} \approx \frac{\alpha+1}{H} \sqrt{7200\left(\frac{H}{60}+e^{\frac{-H}{60}}-1\right)} \\
& B_{1}=[B(h)+B(H)] / 2
\end{aligned}
$$

Thus the closed forms of the shear force and bending moment responses at the influence height, $h$, can be derived as

$$
\begin{aligned}
& r_{B S}=C_{B} J_{z B} J_{x B} R_{B S} \\
& r_{B M}=C_{B} J_{z B} J_{x B} H R_{B M}
\end{aligned}
$$

where

$$
\begin{aligned}
& R_{B S}=\frac{H}{1+2 \alpha}\left[1-\left(\frac{h}{H}\right)^{2 \alpha+1}\right]-\frac{t H}{2 \alpha+2}\left[1-\left(\frac{h}{H}\right)^{2 \alpha+2}\right] \\
& R_{B M}=\frac{h}{2 \alpha+1}\left[\left(\frac{h}{H}\right)^{2 \alpha+1}-1\right]+ \\
& \frac{H+h t}{2 \alpha+2}\left[1-\left(\frac{h}{H}\right)^{2 \alpha+2}\right] \frac{H t}{2 \alpha+3}\left[\left(\frac{h}{H}\right)^{2 \alpha+3}-1\right]
\end{aligned}
$$

\subsection{Resonant component and its effects}

The resonant equivalent load can be represented by the inertial force, and be derived as

$$
\begin{aligned}
P_{R}(z)= & m(z) g_{R} \sigma_{\dot{y}_{1}} \varphi_{l}(z)=C_{R}(1-t z / H)^{2}(z / H)^{\beta} \times \\
& {\left[\int_{0}^{H} \int_{0}^{H\left(z z_{0} \int_{0}^{B(z z}\right)} \int_{0}^{\alpha+\beta}\left(\frac{z_{I}}{H}\right)^{\alpha+\beta}\left(\frac{z_{3}}{H}\right)^{\alpha+\beta} R_{z} R_{x} d x_{l} d x_{2} d z_{l} d z_{2}\right]^{\prime \prime} }
\end{aligned}
$$

where

$$
\begin{aligned}
& C_{R}=\frac{g_{R} \rho C_{d} \bar{U}_{H} \sqrt{\pi f_{1} S_{u}\left(f_{1}\right) /\left(4 \zeta_{1}\right)}}{H\left(\frac{1}{2 \beta+1}-\frac{t}{\beta+1}+\frac{t^{2}}{2 \beta+3}\right)} \\
& g_{R}=\sqrt{2 \ln \left(f_{t} T\right)}+\frac{0.577}{\sqrt{2 \ln \left(f_{t} T\right)}}
\end{aligned}
$$

The simplified expression of Eq.(19) can be written as

$P_{R}(z)=C_{R} J_{z R} J_{x R}(1-t z / H)^{2}(z / H)^{\beta}$

where

$$
\begin{aligned}
J_{x R}= & \sqrt{\int_{0}^{B} \int_{0}^{B} R_{x}\left(x_{1}, x_{2}\right) d x_{1} d x_{2}}= \\
& \sqrt{5000\left(\frac{B_{2}}{50}+e^{-B_{1} / 50}-1\right)} \\
J_{z R}= & \sqrt{\int_{0}^{H} \int_{0}^{H}\left(\frac{z_{1}}{H}\right)^{\alpha+\beta}\left(\frac{z_{2}}{H}\right)^{\alpha+\beta} R_{z}\left(z_{1}, z_{2}\right) d z_{1} d z_{2}} \approx \\
& \frac{0.5 \alpha+1}{1.5 \alpha+\beta+1} \sqrt{7200\left(\frac{H}{60}+e^{\frac{H}{60}}-1\right)}
\end{aligned}
$$

$B_{2}=B(H / 2)$ is the width at half height of the building.

Accordingly, the shear force and bending moment responses at the influence height $h$ under the resonant equivalent wind load are respectively as

$$
\begin{aligned}
r_{R S}= & C_{R} J_{z R} J_{x R} H \frac{1}{\beta+1}\left\{\left[1-\left(\frac{h}{H}\right)^{2 \beta+1}\right]-\right. \\
& \left.\frac{2 t}{\beta+2}\left[1-\left(\frac{h}{H}\right)^{2 \alpha+2}\right]+\frac{t^{2}}{\beta+3}\left[1-\left(\frac{h}{H}\right)^{\beta+3}\right]\right\} \\
r_{R M}= & C_{R} J_{z R} J_{x R} H^{2} \times\left\{-\frac{h}{(\beta+1) H}\left[1-\left(\frac{h}{H}\right)^{\beta+1}\right]\right. \\
& +\left(1+\frac{2 t h}{H}\right) \frac{1}{\beta+2}\left[1-\left(\frac{h}{H}\right)^{\beta+2}\right]-\left(2 t+\frac{t^{2} h}{H}\right) \times \\
& \left.\frac{1}{\beta+3}\left[1-\left(\frac{h}{H}\right)^{\beta+3}\right]+\frac{t^{2}}{\beta+4}\left[1-\left(\frac{h}{H}\right)^{\beta+4}\right]\right\}
\end{aligned}
$$

\subsection{Resultant response}

When the mean, background and resonant response components of the building under the 
equivalent wind load components are computed, the resultant peak load effects can be combined by these components using the following equation:

$$
r=\bar{r}(z)+\sqrt{\left(r_{B}(z)\right)^{2}+\left(r_{R}(z)\right)^{2}}
$$

\section{COMPARISON BETWEEN THE RESPONSES DUE TO EQUIVALENT WIND LOADS FROM DIFFERENT METHODS}

GLF method has been widely applied in the current codes and standards of almost all the countries. In Chinese code [8], Inertial Wind Load method (hereafter referred to as IWL method) has been adopted. Presently Zhou et al made a detailed discussion about GLF and IWL methods [5], and then proposed MGLF method (Moment based GLF method)[6]. In order to further investigate the precision of the present practical method for the equivalent wind load estimations, the Response Deviation Factor (RDF) is defined as

$D=\left(\frac{r_{E}}{r_{E a}}-1\right) \times 100 \%$

where $r_{E a}$ is the response under the actual equivalent wind loads; $r_{E}$ is the response under the approximately estimated equivalent wind loads using different method mentioned above.

12 representative buildings in China are taken as examples to compare the response deviation factors of these methods. Here only the two examples are discussed. The main parameters of these two buildings are given in Table 1 .

The computational results indicate that for the rigid building the RDFs of the background shear force and moment from IWL method are generally much larger than those from the other methods while RDFs of the resonant shear force and moment from GLF method are much larger than those from the other methods. The RDFs of the resultant shear forces and moments are shown in Fig.1.

For the tall building, the RDF values of the background shear forces and moments from MGLF and GLF methods are rather large; while the RDF values of the resonant responses from GLF method are larger than those from the other methods. The $\mathrm{RDFs}$ of the resultant shear forces and moments are shown in Fig.2.

\section{GUST LOADING FACTOR}

As we know, the background and the resonant wind load components can be written as

$$
\begin{aligned}
& P_{B}=G_{B} \bar{P} \\
& P_{R}=G_{R} \bar{P}
\end{aligned}
$$

The resultant wind load can be approximately computed using the following equation:

$$
P=\bar{P}+\sqrt{P_{B}^{2}+P_{R}^{2}}=\bar{P}\left(1+\sqrt{G_{B}^{2}+G_{R}^{2}}\right)
$$

Based on Chinese code [8] and the above discussions, the wind loading factor, $G$, can be derived as

$$
G=1+\lambda_{1} \lambda_{2} \lambda_{3}
$$

where

$$
\begin{aligned}
& \lambda_{1}=0.5 \times 35^{1.8(\alpha-1.6)}\left(\frac{H}{10}\right)^{-\alpha} \frac{\sqrt{7200\left(\frac{H}{60}+e^{-\frac{H}{60}}-1\right)}}{H} \\
& \lambda_{2}=\frac{\sqrt{5000\left(\frac{B_{0}}{50}+e^{-\frac{B_{0}}{50}}-1\right)}}{B_{0}} \\
& \lambda_{3}=\sqrt{[(\alpha+1)]^{2}+\left[\eta \frac{(0.5 \alpha+1)(2 \beta+1)}{1.5 \alpha+\beta+1}\left(\frac{z}{H}\right)^{\beta-2 \alpha}\right]^{2}}
\end{aligned}
$$

For convenience, $\lambda_{1}, \lambda_{2}$ and $\lambda_{3}$ have been numerically computed and the results are given in table style.

\section{CONCLUDING REMARKS}

This paper proposes a simplified method for estimating background and resonant equivalent wind loads on buildings. These formulas are not relative to the type of response. 2 representative buildings are computed to investigate the precision of the formulas. The computational results show that the present formulas have higher precision than GLF and IWL methods. Based on the Chinese code and the present simplified formulas, a new equation of gust loading factor is finally presented.

\section{Acknowledgements}

This project is jointly supported by National Science Foundation for Outstanding Youth, National Natural Science Foundation (59895410) and Foundations for University Key Teacher by the Ministry of Education, which are gratefully acknowledged.

\section{References}

1) A. G. Davenport, Gust loading factors. J Struct Div, ASCE, 93(ST3), 1967: 11-34

2) ASCE. Minimum Design Loading for Buildings and Other Structures. ANSU/ASCE793, 1994

3) NRCC. User's Guide-NBC 1995 Standard Commentaries. 1996

4) Architectural Institute of Japan. Recommendations for Loading on Buildings. RLB-AIJ 1993 (English version), 1996

5) Y. Zhou, M. Gu and H. F. Xiang, Alongwind static equivalent wind loads and responses of 
tall buildings. Part I: Unfavorable distribution of static equivalent wind loads. J Wind Eng \& Ind Aerodyn, 97, 1999: 135-150

6) Y. Zhou, A. Kareem and M. Gu, Gust loading factors for design applications. In: Proc. of the $10^{\text {th }}$ Int. Conf. on Wind Eng, Copenhagen, Denmark, 1, 1999: 169-178

7) G.Piccardo and G.Solari ,3D Wind-Excited Response of Slender Structures: Closed-Form Solution, Journal of Structural Engineering, August 2000, Vol.126, No.8, PP936-943
8) X. T. Zhang, Handbook for Wind-Resistant design of Engineering Structures, China Architectural Industrial Publisher, 1998 (in Chinese)

9) Chinese Code of Loading on Buildings and Other Structures. GBJ 9-87, 1990 (in Chinese)

Key words: Tall building, Along-wind equivalent wind load, Background component, Resonant component, Response

Table 1 Main parameters of the two example buildings

\begin{tabular}{|c|c|c|c|c|c|}
\hline No. & Hight(m) & $\begin{array}{c}\text { Base width } \\
(\mathrm{m})\end{array}$ & $\begin{array}{c}\text { Exponent of the } \\
1^{\text {st }} \text { mode shape }\end{array}$ & The $1^{\text {st }}$ frequency(Hz) & Damping ratio \\
\hline 1 & 80 & 20 & 1.2 & 0.55 & 0.05 \\
\hline 2 & 240 & 42 & 1.0 & 0.2 & 0.02 \\
\hline
\end{tabular}

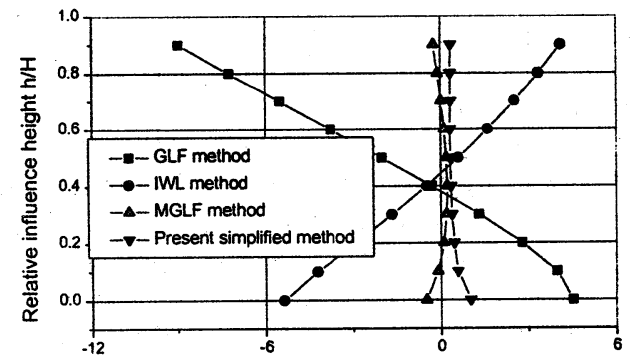

(c) Resultant shear force deviation factor (\%)

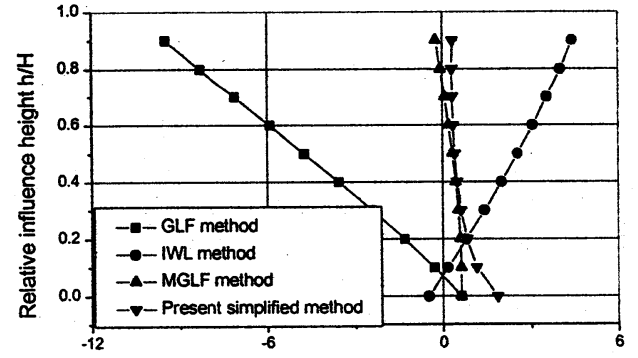

(f) Resultant moment deviation factor (\%)

Fig.1 Comparison of RDFs of the rigid building using different methods

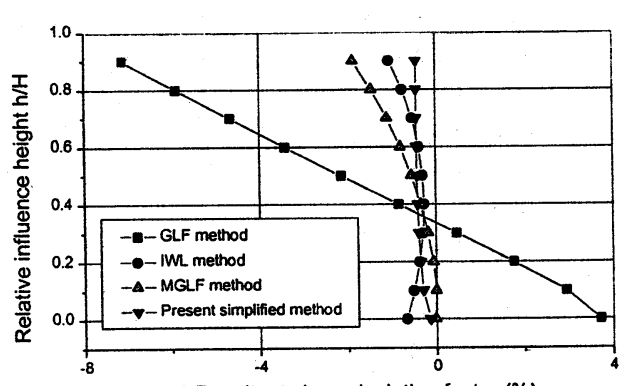

(c) Resultant shear deviation factor (\%)

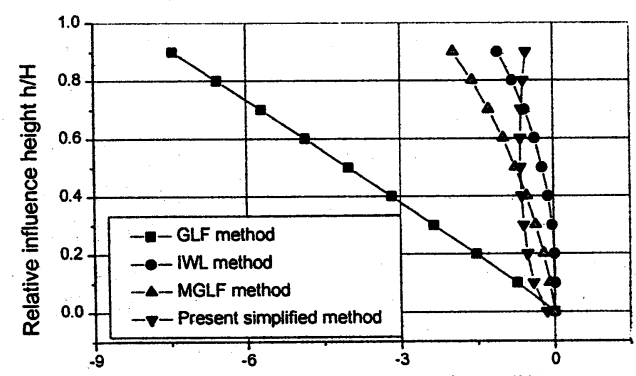

(f) Resultant moment deviation factor (\%)

Fig.2 Comparison of RDFs of the tall building using different methods 


\title{
WIND LOADS ON HIGH-RISE STRUCTURES \\ - COMPARATIVE STUDY OF CODE PROVISIONS ACCORDING TO EUROCODE 1 AND CHINESE CODES
}

\author{
Zhuo Hui ${ }^{1)}$, Andreas Bachmann ${ }^{2)}$ and Carl-Alexander Graubner ${ }^{2)}$ \\ 1) College of Civil Engineering, Southeast University Nanjing, P.R. China \\ 2) Institute for Concrete Structures and Materials, Darmstadt University of Technology, Germany
}

\section{INTRODUCTION}

High-rise building construction is an increasing market both in Europe and in Asia. The bending moments on the building caused by wind load increase with the square of the height, and so for high-rise structures, structural design depends mainly on the effects of wind loading. In recent years, the problems of wind loading have been researched as one of main study directions. Aim of this paper is a comparative study of code provisions regarding wind actions on high-rise buildings according to Eurocode 1 [1] as well as several Chinese codes[2][3][4].

Starting with the coincident formulation of wind load in along-wind direction, distinctions in assuming reference wind velocity respectively wind velocity pressure are pointed out. The logarithmic law according to Eurocode 1 and the power law model in Chinese code to describe the vertical profile of mean wind velocity are faced each other. The latter incorporates a much faster increase of static wind load with rising height. Coefficients considering the dynamic wind properties as well as oscillation behaviour of the building itself are discussed from theory and comparative calculations. An example is given for a survey of the total effect. Aerodynamic shape coefficients usually are derived from wind tunnel experiments and therefore aren't considered further on.

\section{FORMULATION OF ALONG-WIND ACTION}

The global wind pressure $\mathrm{w}_{\text {ref }}$ in along-wind direction according to Eurocode 1 and Chinese code is obtained from the equations

$$
\begin{aligned}
& w_{\text {ref }}=q_{\text {ref }} \cdot c_{e}(z) \cdot c_{d} \cdot c_{f} \\
& w_{k}=w_{0} \cdot \mu_{z} \cdot \beta_{z} \cdot \mu_{s}
\end{aligned}
$$

where $\mathrm{q}_{\mathrm{ref}}$ and $\mathrm{w}_{0}$ are the reference mean wind velocity pressure. The factors $c_{e}(z)$ respectively $\mu_{z}$ consider the influence of height above ground as well as surface roughness on the vertical wind profile, correlation and dynamic magnification due to wind are contained in the factors $c_{d}$ respectively $\beta_{z}$. Factors $c_{f}$ and $\mu_{s}$ are the aerodynamic force coefficients in order to incorporate the shape of the structure.

Obviously in principle the formulation of wind pressure in along-wind direction is the same in both codes.

\section{REFERENCE WIND VELOCITY}

The reference wind velocity $\mathrm{v}_{\text {ref }}$ according to Eurocode 1 depends on the basic value of the reference wind velocity $v_{\text {ref, } 0}$ which is modified by some factors considering direction, season and altitude of terrain. $v_{\text {ref }, 0}$ is given at an altitude $10 \mathrm{~m}$ above ground, with an averaging period of 10 
minutes, a statistical mean return period of 50 years and for the roughness category "open terrain".

The basic wind pressure $w_{0}$ in Chinese code is defined as the same as Eurocode 1, but with a return period of once-in-30-years. The presumed basic value of wind pressure respectively wind velocity is up to a third higher than in Europe. The reason is that Europe has a more temperate climate, whereas the Chinese coast is exposed to strong typhoons.

There are differences both in the supposed return period and in return period conversion functions. In Eurocode 1 the following formula for transformation of wind velocity into other return periods is given

$$
\begin{aligned}
\frac{q_{\text {ref }}(p)}{q_{\text {ref }}(50)} & =\left\{\frac{1-K_{1} \cdot \ln [-\ln (1-p)]}{1-K_{1} \cdot \ln [-\ln 0.98]}\right\}^{n} \\
& =\left\{\frac{1-0.2 \cdot \ln [-\ln (1-p)]}{1-0.2 \cdot \ln [-\ln 0.98]}\right\}^{0.5}
\end{aligned}
$$

whereas the Chinese code adopts the equation 4.

$$
\mu_{\mathrm{T}}=0.3631 \cdot \lg \mathrm{T}_{0}+0.463
$$

This is because they are fitted by different experimental and testing data, and based on different theory supposition. At the same time, many factors influence them.

\section{VERTICAL WIND PROFILE}

The exposure factor $c_{e}(z)$ according to Eurocode 1 takes into account both the vertical distribution of mean wind velocity and gust action described by the height dependent turbulence intensity $I_{v}(z)[5]$. Therefore it consists of a roughness coefficient $c_{r}(z)$, a topography coefficient $c_{t}(z)$ as well as a magnification factor due to gust acting. Merely the square of roughness coefficient $c_{r}(z)$ should be used for comparison of code height factors. The wind profile in Eurocode 1 is specified using a natural logarithm law. But in Chinese code the power law model is used to describe the mean wind profile by means of the height factor $\mu_{\mathrm{z}}$.

$$
\begin{aligned}
& c_{e}(z)=c_{r}^{2}(z)=k_{r}^{2} \cdot \ln ^{2}\left(\frac{z}{z_{0}}\right) \\
& \mu_{z}(z)=3.12 \cdot\left(\frac{z}{H_{T}}\right)^{2 \alpha}
\end{aligned}
$$

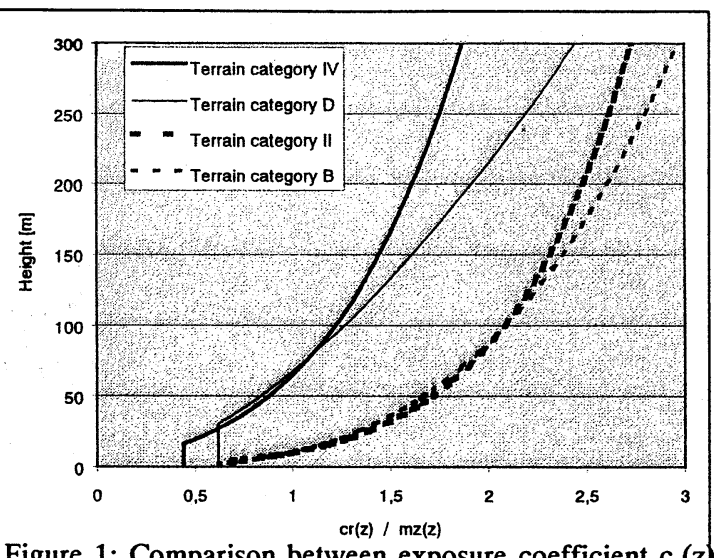

Figure 1: Comparison between exposure coefficient $c_{c}$ (z) according to Eurocode 1 for terrain categories II and IV and height factor $\mu_{z}$ according to Chinese code for terrain categories $B$ and $D$

where $\mathrm{H}_{\mathrm{T}}$ is the gradient height for this terrain.

A comparison of the height factors is shown in figure 1 . Conformity of both code factors can be observed up to a height of $100 \mathrm{~m}$ only. For upper altitudes Eurocode 1 provides much lower height factors than the Chinese code. The effect is significantly increased with rising height.

\section{DYNAMIC WIND PROPERTIES}

Usually wind load is not of a steady nature, but it's rather a stochastic process. The phenomenon is taken into account by introducing a dynamic gust factor. This factor incorporates into wind load formulation both reduction effects due to the lack of correlation of maximum pressure over large surface areas and magnification of static load due to oscillations of the building depending on its structural dynamic properties.

Already the exposure coefficient $c_{e}(z)$ according to Eurocode 1 contains the influence of wind turbulence intensity depending on height above ground. In order to take dynamic effects into consideration the code offers two alternative procedures to establish the dynamic coefficient $c_{d}$, a simple and a detailed one. The simple procedure is valid for structures of slight dynamic sensitivity only, meaning dynamic coefficients $c_{d}$ smaller than 1.2. It assumed very common values of wind velocity, terrain, frequency and damping. The detailed procedure is advised to be used for high-rise buildings, it has been formulated as

$$
c_{d}(z)=\frac{1+2 \cdot g \cdot I_{v}(z) \cdot \sqrt{Q_{0}^{2}+R_{x}^{2}}}{1+7 \cdot I_{v}(z)}
$$


where the turbulence intensity $\operatorname{Iv}(\mathrm{z})$, the resonant response part $R_{x}$, the background response part $Q_{0}$ and the peak factor $g$ are defined respectively by some formulae. Besides these, other parameters in these formulae have their own theory formulae[6]. From mentioned above, wind and structural parameters is given by a set of quite complicated equations in Eurocode. For these comparative studies only the numerator of the given fraction number is considered. The only task of the denominator is to remove turbulence intensity used as a factor within the exposure coefficient in the simple procedure for dynamic coefficient.

The gust-loading factor $\beta_{z}$ according to the Chinese Loading Code is equal to the ratio of the peak loading to the mean loading. The formula of $\beta_{z}$ has been derived from the random vibration theory due to wind action. Chinese Loading Code adopted Davenport's approximate formula for wind spectrum density depending on practical measurements and Shiotani's experimental data for correlation functions. Under the condition of satisfying China's reliability index and only considering the first vibration mode, we get the formula

$$
\beta_{z}=1+\frac{\xi \cdot v \cdot \varphi(z)}{\mu_{z}}
$$

where $\xi$ means a fluctuating amplification factor, $v$ is a factor taking account of the influence of fluctuating wind pressure varying along the height, $\varphi(z)$ is the factor of the first vibration mode of structure whose cross section is constant along the height.

As it is to be seen, gust-loading coefficient calculation is very different in both codes. We have compared the differences in the derivation of the random vibration theory as well as selection of the formulae and parameters. Results of parameter studies in order to compare the gust factors according to both codes are shown in Fig2 5. $\left(\mathrm{b}_{z}=\beta_{z}\right)$

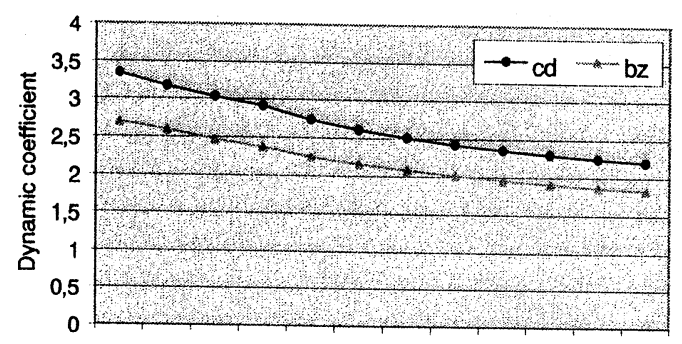

$\begin{array}{llllllllllll}50 & 60 & 70 & 80 & 100 & 120 & 140 & 160 & 180 & 200 & 220 & 240\end{array}$ Height

Figure 2: Dynamic coefficient change with varying height of the structure

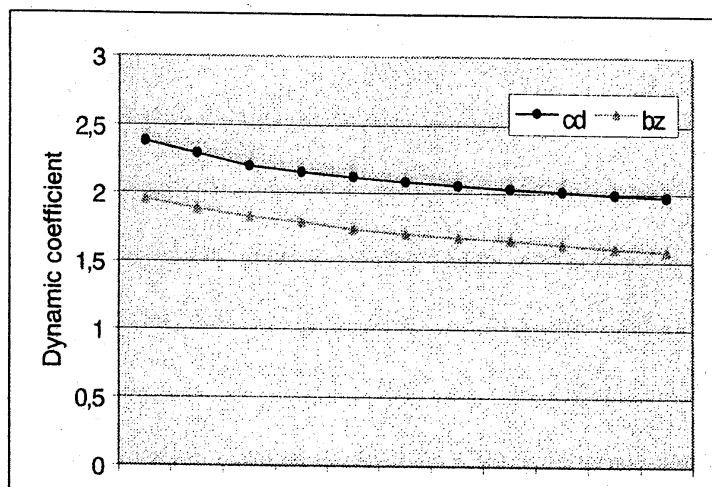

$\begin{array}{lllllllllll}30 & 50 & 80 & 100 & 120 & 140 & 160 & 180 & 200 & 220 & 240\end{array}$

Width

Figure 3: Dynamic coefficient change with varying width of the structure

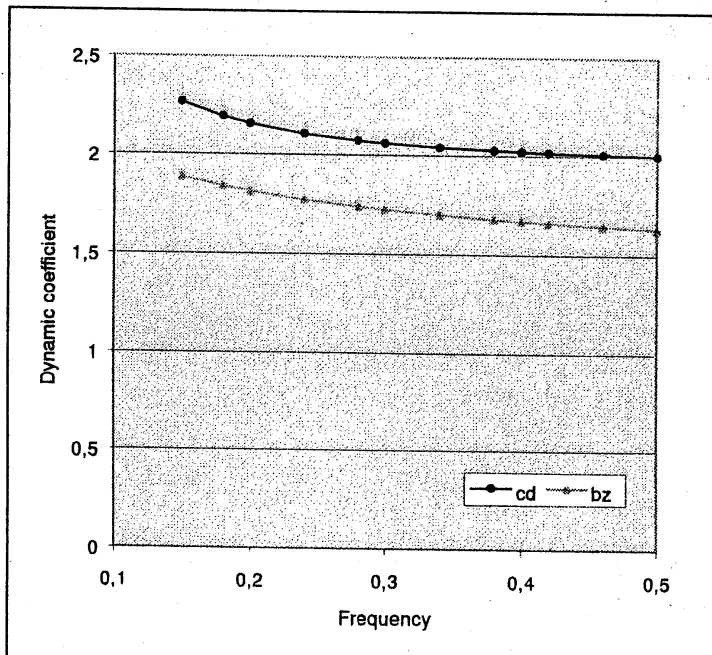

Figure 4: Dynamic coefficient change with varying frequency of the structure

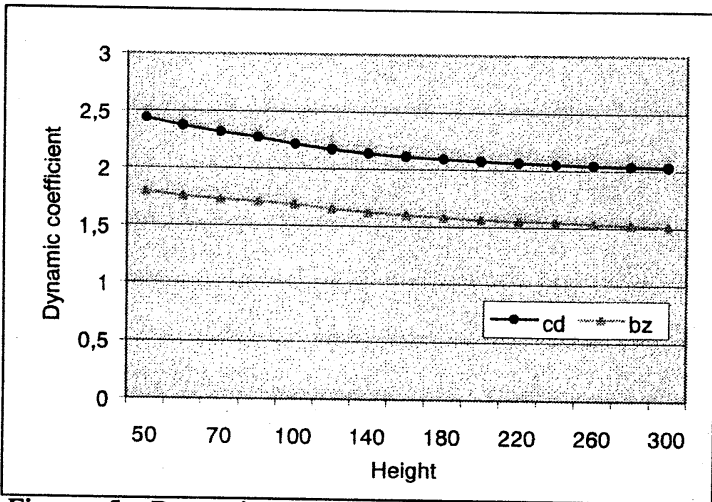

Figure 5: Dynamic coefficient change with varying height and fundamental period of the structure incorporating the respective formula of height-dependent fundamental period according to Eurocode 1 and Chinese code 
From the curves above, it can be observed that Eurocode1 has for every arrangement a much higher value of dynamic coefficient than Chinese code's one.

\section{TOTAL EFFECT IN ALONG-WIND DIRECTION}

A comparative study of the total effect of alongwind load on high-rise buildings according to both codes has been carried out, considering an example of a reinforced concrete structure of fundamental natural frequency $f=0.19 \mathrm{~Hz}$ as well as logarithmic damping decrement $\delta=0.10$, situated within the terrain category 'city centre' with a total height of $200 \mathrm{~m}$ and a squared ground plan of width $40 \mathrm{~m}$. The reference wind velocity is $24.3 \mathrm{~m} / \mathrm{s}$. According to Eurocode1 the shear force $Q$ and bending moment $M$ at the restraint point at the bottom of the structure can be gained with the help of the integration formulae,

$$
\begin{aligned}
& Q=\int_{0}^{H} q_{\text {ref }} \cdot c_{f} \cdot c_{e}(z) \cdot c_{d} \cdot b_{\text {ref }} \cdot d z \\
& M=\int_{0}^{H} q_{\text {ref }} \cdot c_{f} \cdot c_{e}(z) \cdot c_{d} \cdot z \cdot b_{\text {ref }} \cdot d z
\end{aligned}
$$

finally resulting in

$$
\begin{aligned}
& \mathrm{Q}=9.97 \mathrm{MN} \\
& \mathrm{M}=1330.04 \mathrm{MNm} .
\end{aligned}
$$

According to Chinese code, the structure is divided into 10 equal parts along the height. Accumulating every part's contribution to shear force $Q$ and total bending moment $\mathrm{M}$ at the bottom of the structure by formulae,

$$
\begin{aligned}
& Q=\sum_{i=1}^{10} Q_{i} \\
& M=\sum_{i=1}^{10} M_{i}
\end{aligned}
$$

generates the results

$$
\begin{aligned}
& \mathrm{Q}=8.65 \mathrm{MN} \\
& \mathrm{M}=1132.09 \mathrm{MNm} .
\end{aligned}
$$

Obviously it can be seen that the value of shear force and bending moment according to Eurocode 1 is approximately $15 \%$ higher than the Chinese code one.

Finally, total along-wind load effect on structure is pictured as a survey of both codes, and many examples will be given to have a quantity conception of along-wind load acting on high-rise building according to both codes.

\section{CONCLUSION}

1) The principle of the formulation of wind pressure is the same in both codes.

2) Reference wind velocity for Chinese coastal areas has to be assumed significant higher than in Europe. Inner-continental values are similar.

3) Because of the return period conversion functions are fitted by different data and based on different theory supposition, there are differences in the return period conversion formulae.

4) For upper altitudes Eurocode 1 provides much lower height factors than the Chinese one. The effect is significantly increased with rising height.

5) Gust-loading coefficient of Chinese code is always lower than Eurocode 1.

6) Total wind load on a high-rise building according to Chinese code is lower than according to Eurocode1.

\section{References}

1) CEN European Committee for Standardisation: Eurocode1, Basis of Design and Actions on Structures, Part 2.4: Wind Actions. CEN Steering Panel Draft, 1994.

2) The Ministry of the Environment Protection and the Building of the Town and Country of China: Chinese Loading Code GB J 9-87. China Plan Press, 1989.

3) The Building Ministry of China: Design and construction specifications for reinforced concrete high-rise structures JGJ 3-91. China Building Industry Press, 1991. (in Chinese)

4) The Building Ministry of China: Technical Specification for Steel Structures of Tall Buildings JGJ 99-98. China Building Industry Press, 1998.

5) Emil Simiu, Robert H Scanlan.: Wind Effects on Structures (Fundamentals and Applications to Design), John Wiley \& Sons Inc, 1996

6) Claes Dyrbye, Svend O. Hansen.: Wind Loads on Structure, John Wiley \& Sons Inc, 1996.

key words: wind load, gust factor, along-wind action, Chinese code, Eurocode 1, high-rise building 